\title{
Evaluation Teaching Performance of Faculty Members at the Faculty of Education, University of Sirte in Libya From the View Point of College Students as an Approach to Achieve Quality of University Education
}

Amhaimmed Omar Amhaimmed Essa

Education and Psychology - College of Education

Sirte University - Libya

dr.m.omar67@gmail.com

\author{
Hassan Salm Ahmed Alshahopi \\ Education and Psychology - College of Education \\ Misurata - Libya \\ alshahopi@yahoo.com
}

Received 27/8/2019

Accepted 25/9/2019

\section{Abstract:}

The present study aims to evaluate the teaching performance of the faculty member at the Faculty of Education, University of Sirte, from the point of view of the students of the faculty as an approach to achieve quality in university education. The study uses the descriptive analytical method using the evaluation card of the faculty member in the fields of lecture planning, preparation, human relations, and evaluation methods. The study reached a number of conclusions, most notably:

- Evaluation of the performance of the faculty member at the Faculty of Education is moderate, reflecting the dissatisfaction of students with this performance.

- There are no statistically significant differences at the level of 0.01 due to the variables of gender, the semester, and the course in their responses about evaluating the performance of the faculty member.

- There are statistically significant differences at the level of significance 0.05 for the variable of the scientific departments in the responses of students about the evaluation of the performance of the faculty member of the Faculty of Education in favor of the departments of (Mathematics, Chemistry, Physics, and Biology).

Keywords: Evaluation, Teaching Performance. 


\section{تقويم الأداء التدريسي لعضو هيئة التدريس بكلية التربية جامعة سرت في ليبيا من وجهة نظر طلبة الكلية كمدخل لتحقيق جودة التعليم الجامعي}

\author{
حسن سالم احمد الثهوبي \\ التربية وعلم النفس - كلية التربية \\ جامعة مصراته - ليييا \\ alshahopi@yahoo.com
}

\author{
امحمد عمر امحمد عيسى \\ التربية وعلم النفس - كلية التربية \\ جامعة سرت - ليييا \\ dr.m.omar67@gmail.com
}

قبول البحث

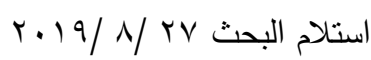

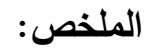

هدفت الدراسة الحالية إلى تقويم الأداء التدريسي لعضو هيئة التدريس بكلية التربية جامعة سرت من وجهة نظر طلبة الكلية كمدخل لتحقيق

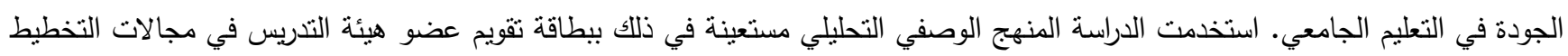
للمحاضرة والاستعداد لها وفي العلاقات الانسانية واساليب النقويم المتبعة، وتوصلت الدراسة إلى مجموعة من النتائج أبرزها:

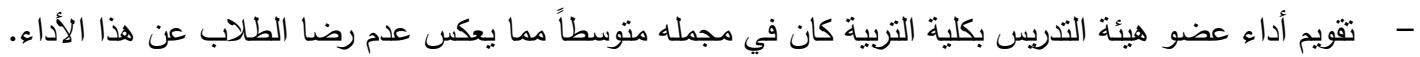
- عدم وجود فروق ذات دلالة إحصائية عند مستوى دلالة ال.,. • تعزى لمتغير جنس الطلاب والفصل الدراسي والمقرر الدراسي في استجاباتهم حول تقويم أداء عضو هيئة التدريس. هناك فروقٌ ذات دلالة إحصائية عند مستوى دلالة هـ ه. . • لمتغير الأقسام العلمية في استجابات الطلاب حول تقويم أداء عضو هيئة التدريس بكلية النربية لصالح أقسام (الرياضيات - الكيمياء - الفيزياء - الأحياء). الكلمات المفتاحية: التقويم، الأداء التدريسي.

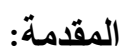

وقد اهتمت ليبيا بالتعليم الجامعي- من خلال التوسع في عدد

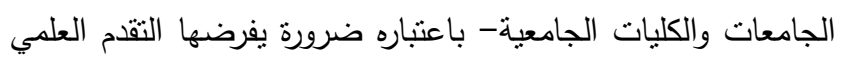

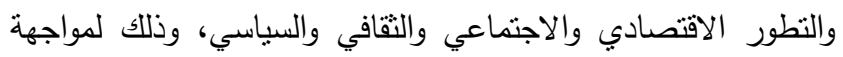

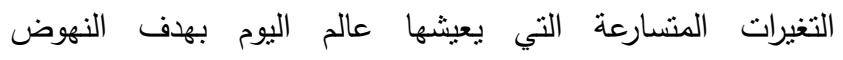

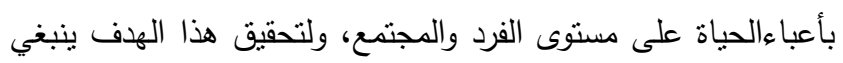

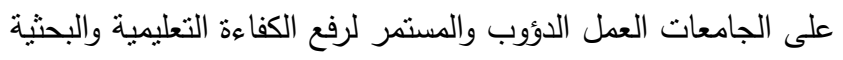

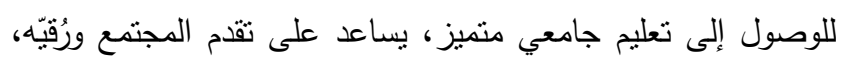

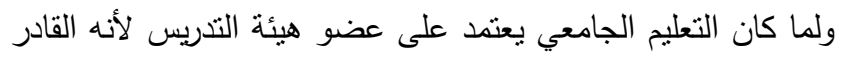

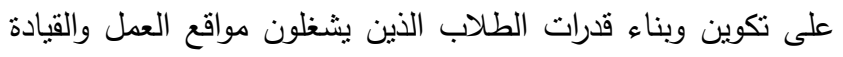

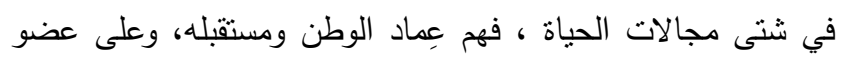
هيئة التدريس تقع أدوار مهمة في غرس القيم الحميدة والأخلاق الحسنة والعلوم والمعارف النافعة في نفوس طلابه بما يكفل إعدادهم

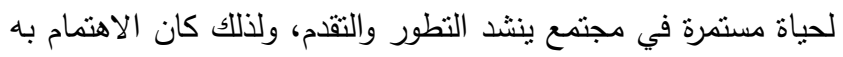

تسعى دول العالم كافة إلى الارتقاء والتقدم في شتى مجالات

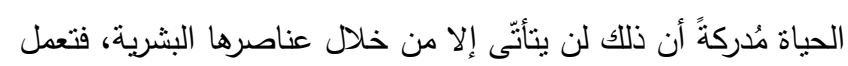

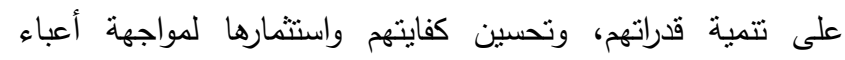
الحياة،خاصة في عصر يشهة العديد من المتغيرات والتحديات العلمية

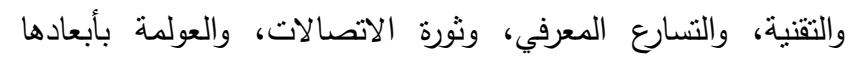
الهختلفة السياسية، والاقتصادية، والاجتماعية، والثقافية.

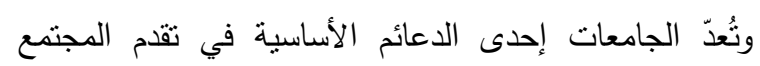

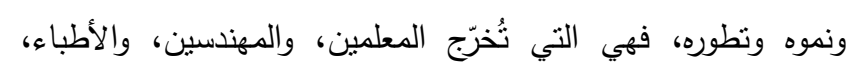
ورجال السياسة والقانون والاقتصاد والأدب والفنون...الخ. ونظراً للدور

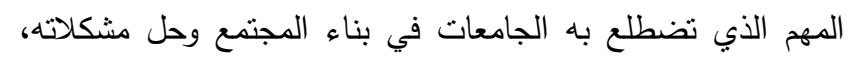

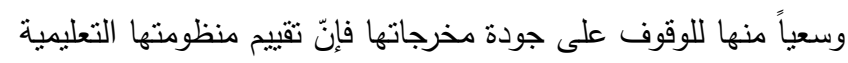

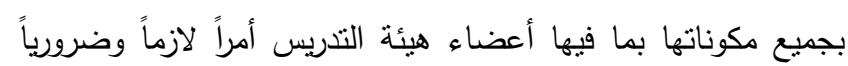

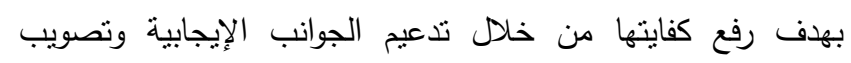

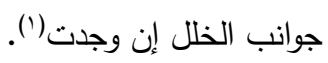




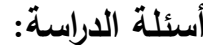

تسعى الدراسة الحالية للإجابة عن التساؤلات التالية:

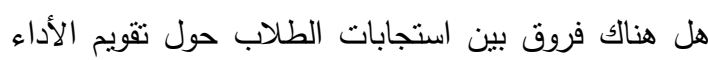
التدريسي لعضو هيئة التدريس تُعزى لمتغير الفصل

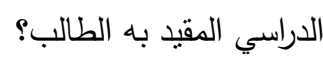
هل هناك فروق بين استجابات الطلاب حول تقويم الأداء التدريسي لعضو هيئة التدريس تُعزى لمتغير جنس الطالب؟ هل هناك فروق بين استجابات الطلاب حول تقويم الأداء

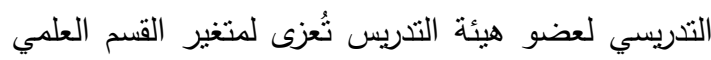

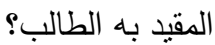
هل هناك فروق بين استجابات الطلاب حول تقويم الأداء التدريسي لعضو هيئة التدريس تُُزى لمتغير المادة الدراسية

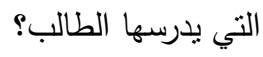

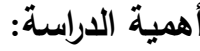

تتبع أهمية هذه الدراسة من كونها تلقي الضوء على إحدى التى التهاء

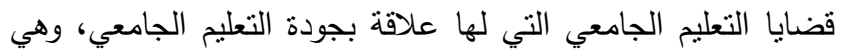

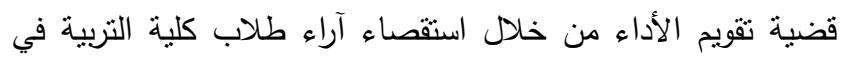
تقويم أداء عضو هيئة النكريس بالكلية، والكثف عن أوداء لأنه القصور في مستوى الأداء التدريسي لعضو هيئة التدريس وتحديدها ومعالجتها،

كما تكثف عن الجوانب الإيجابية وتعزيزها.

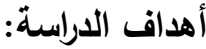

$$
\text { تهدف الدراسة الحالية إلى التعرف إلى: }
$$

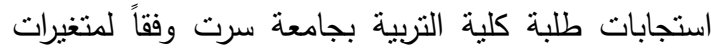

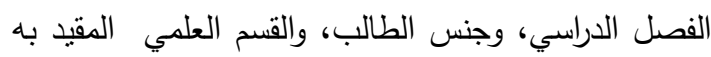
الطالب، والمادة الدراسية التي يدرسها الطالب حول تقويم

$$
\text { الأداء التدريسي لعضو هيئة التدريس. }
$$

أوجه القصور في مستوى الأداء التدريسي لعضو هيئة لكئة

التدريس بالكلية من وجهة نظر الطلاب وكيفية معالجتها. الجوانب الإيجابية لدى عضو هيئة التدريس من وجهة نظر

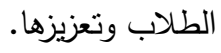

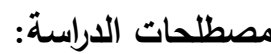

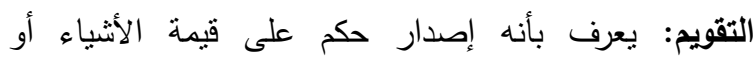

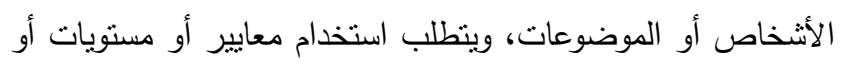

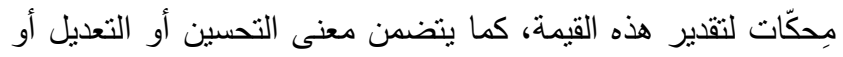
النطوير الذي يعتمد على هذه الأحكام(؟). تقويم الأداء: يعرف بأنه تقرير دوري يبين مستوى أداء الفرد

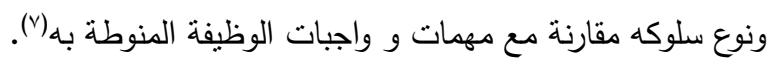
وهناك من بعرفه بأنه تقدير كفاءة الفرد في عمله بغرض معرفة مدى صلاحيته في القيام بأعباء وظيفته ومستوى أدائه لواجباته،
من حيث اختياره بمواصفات ومعايير معينة من بين المتفوقين الذين

أكملوا دراستهم الجامعية ومن ثمّ تأهيلهم نفسياً وتربوياً واجتماعياً (؟).

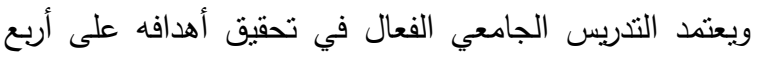
دعائم أساسية هي: الطالب، وعضو هيئة التدريس، والمنهج، والإدارة، و لا يمكن أن يتحقق نجاح عملية التدريس بالجامعات إلا من خلال الارتقاء بتلك الدعائم والمكونات إلى مستوى الأهداف التي تضعها لإناه

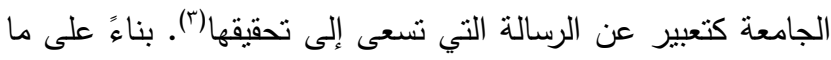

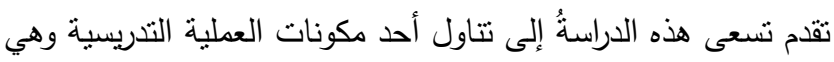
عملية تقويم الأداء التدريسي لعضو هيئة التدريس من وجهة نظر لإلى طلابه بكلية التربية جامعة سرت باعتبارها من العمليات الأساسية التي لناهي تهدف إلى زيادة فاعلية أدائه ونظوير قدراته وإمكانياته، وذللك من باعبارها

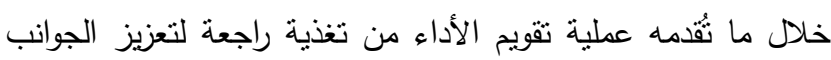
الإيجابية، ومعالجة جوانب الضعف والقصور .

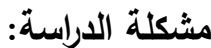

تمتل عملية التقويم في الجامعة ركناً أساسياً في منظومة التعليم الجامعي لأهميتها في بيان مدى تحقيق الأهداف الجامعية المنشودة

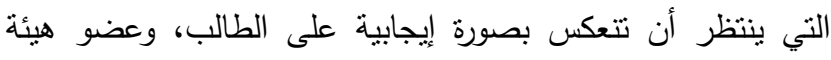

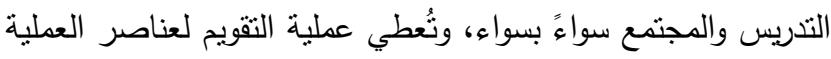

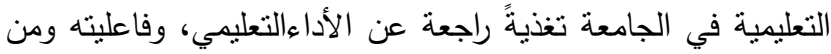
هنا ينت تعزيز عناصر القوة ومكافأتها ومعالجة عناصر الضعف فيها لتحسين الأداء والارتقاء بنوعيته. وقد احتل تقويم أداء أعضاء هيئة التدريس بجوانبه المختلفة مكانة بارزة في مؤسسات التعليم العالي، إذ يساعد أصحاب القرارات

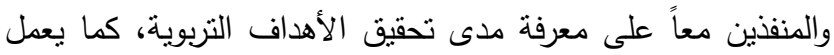
على تحسين نوعية التعليم الجامعي وتطويره من خلال زيادة فاعلية أداء أعضاء هيئة التدريس وفقاً للمستجدات العلمية والحئ والحاجات المجتمعية الطارئة، ويمكن القول بأن مستوى مؤسسات التعليم العالي لئي

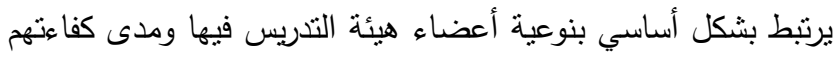

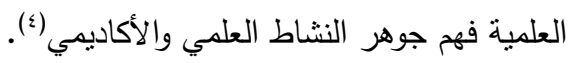
لقد حظي موضوع التقويم الأكاديمي باهتمام كثير من الباحثين

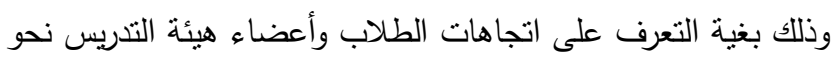
عملية التقويم، وتحديد العوامل المؤثرة فيها، وتطوير مقاييس نتميز

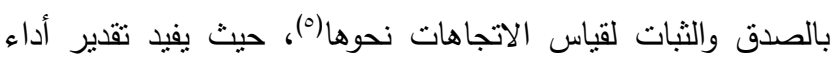

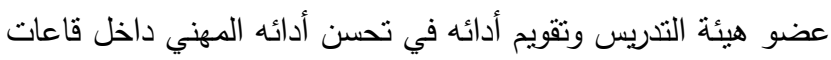

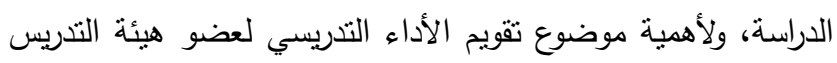

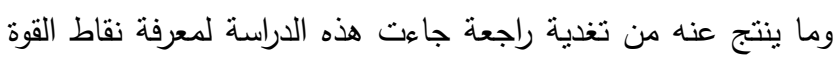
والضعف لعضو هيئة التدريس بكلية التربية بجامعة سرت من وجهة نظر طلبة الكلية في ضوء بعض المتغيرات. 
تللك الدراسات والبحوث، ويعرض الباحثان فيما يلي لهذه الدراسات وفقاً

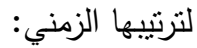

دراسة منسي، محمود عبد الحليم(·) استهوفت هذه الدراسة

إعداد بطاقة لتقويم أستاذ الجامعة من وجهة نظر طلابه لمساعدة عضو هيئة التدريس للتعرف على جوانب القوة والضعف في أدائه من وجهة نظر طلابه، وقام الباحث بتطبيق بطاقة التقويم على عينة من طلاب كلية التربية بالمدينة المنورة بجامعة الملك عبد العزيز، وعينة من طلاب كلية التربية جامعة الإسكندرية، وعلى عينة من المعيدين والمدرسين المساعدين بكلية التربية بجامعة الإسكندرية. ولقد توصلت الإنس الدراسة إلى أن معامل الثبات للبطاقة هو rr, • لطلاب كلية التربية بالمدينة المنورة الذين درسوا مقرر علم النفس التربوي مع الباحث للعام

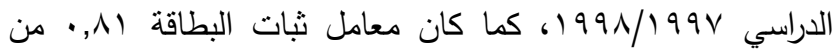
طلاب كلية التربية بالمدينة المنورة الذين درسوا مقرر التعلم والفروق

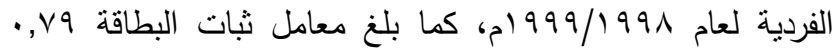
لطلاب كلية التربية جامعة الإسكندرية ممن درسوا مع الباحث مقرر

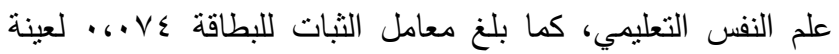

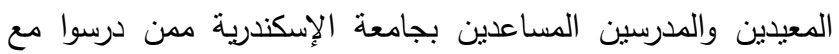

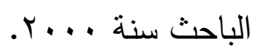

وطوقان، أريج(") ،استهدفت الدراسة التعرف إلى مدى تقويم

الطلبة لأداء أعضاء الهيئة التدريسية ومدى اختلافهم في تقويم

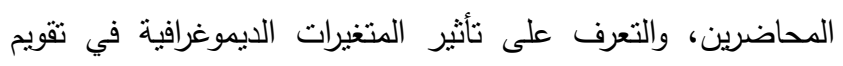
الطلاب لأعضاء هيئة التدريس ومعرفة أهم اقتراحات الطلاب لتحسين الأداء الأكاديمي للمحاضرين، وتوصلت الدراسة إلى أن ترتيب تقويم الطلاب لأعضاء هيئة التدريس حسب أهميتها من وجهة نظرهم: الصفات الثخصية والعلاقات الإنسانية في المرتبة الأولى، وإدارة

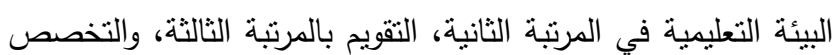
والثقافة العامة بالمرتبة الرابعة. ودراسة: الحكمي، إبراهيم الحسن، (r') هدفت هذه الدراسة إلى لى الى

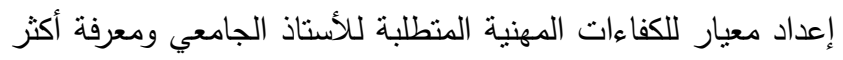

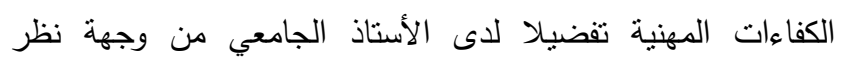

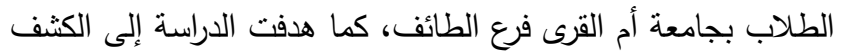

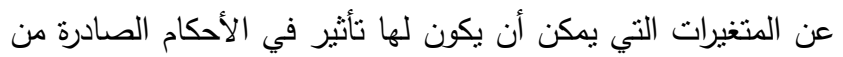

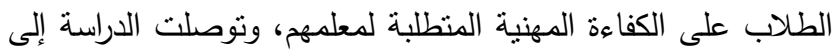

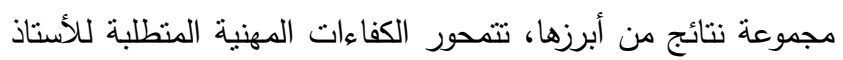

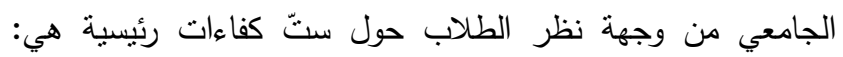
(الثخصية، والإعداد للححاضرة وتتفيذها، والعلاقات الإنسانية،

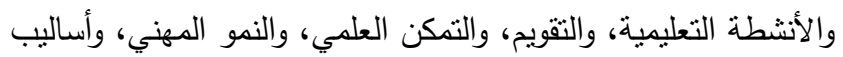

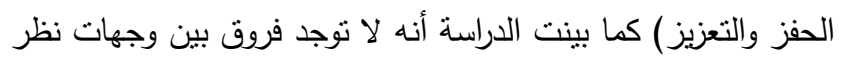

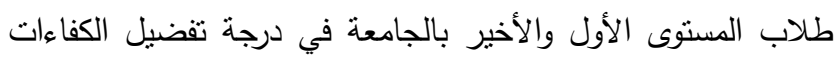

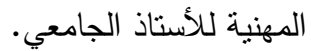

ودرجة تعاونه مع زملائه، وطاعته لرؤسائه وسلوكه نحو المتعاملين

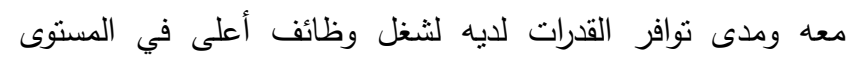
النتظيمي (^). أما تقويم أداء عضو هيئة التدريس فيعرف بأنه العملية التي يتم

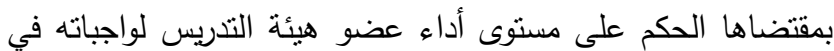
مجالات التدريس، والبحث العلمي، وخدمة المجتمع. عضو هيئة التدريس: يعرف أعضاء هيئة التدريس وفقاً للائحة

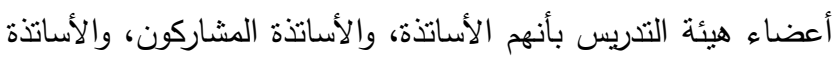
المساعدون، والدحاضرون، والمحاضرون المساعدون، ويشترط فيمن يعين عضو هيئة التدريس أن يكون حاصلاً على درجة الإجازة العالية والدقيقة أو ما بعادلها من إحدى الجامعات أو الهيئات العلمية دلإنية

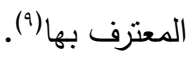

\section{منهج الدراسة:}

تحقيقاً لهدف الدراسة ولإجابة عن تساؤلاتها استخدم الباحثان

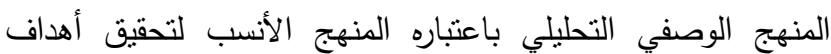
الدراسة حيث من خلاله يستطيع الباحثان وصف وتحليل موضوع العاني

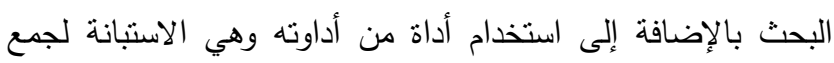

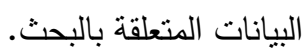

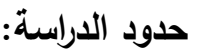

تتحدد الدراسة الحالية بالحدود الآتية: الحد الأكاديمي والموضوعي لهذه الدراسة في تقويم أداء

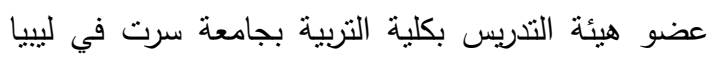
من وجهة نظر طلابها. الحد البشري لهذه الدراسة: تمنل في طلاب الفصل الدراسي

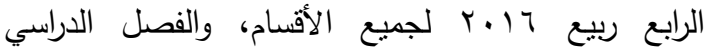
السادس خريف VIV Y بقسم التخطيط والإدارة التربوية.

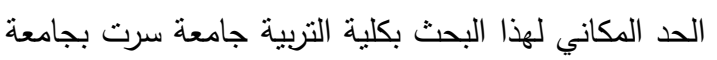

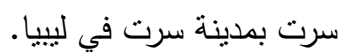
الحد الزماني لهذا البحث بالنسبة لطلاب الفصل الدراسي لئي

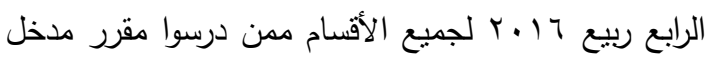
إلى التربية، ولطلاب قسم الإدارة والتخطيط التربوي ممن الترن درسوا مقرر علم السكان خلال فصل الخريف VI V. I.

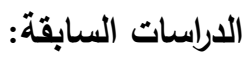

تُعد الدراساتُ السابقة المرتبطة بموضوع الدراسة ذات أهمية

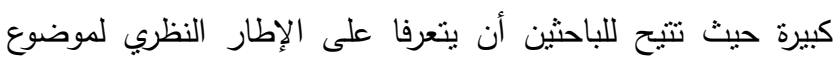

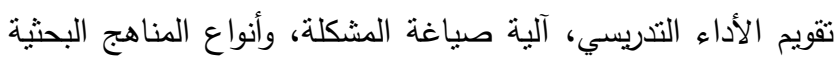

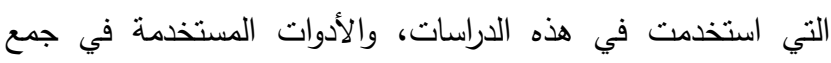
البيانات وطرق المعالجة الإحصائية لهذه البيانات، والنتائج التي لإني

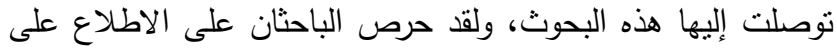


جدول (1) توزيع مجتمع البحث حسب التخصص العلمي والفصل الدراسي وجنس الطلاب.

\begin{tabular}{|c|c|c|c|c|c|c|c|c|c|}
\hline \multicolumn{3}{|c|}{ المجموع } & \multicolumn{3}{|c|}{ 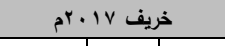 } & \multicolumn{3}{|c|}{ رييع rأبrم } & \multirow{2}{*}{ التضصل الدراسي } \\
\hline المجموع & اناث & ذكور & المجموع & اناث & ذكور & المجموع & اناث & ذكور & \\
\hline$\leqslant v$ & ro & ir & - & - & - & $\leqslant v$ & ro & ir & الكيمياء \\
\hline 10 & ir & r & - & - & - & 10 & ir & $r$ & الرياضيات \\
\hline$\leq 4$ & $r \wedge$ & 11 & - & - & - & rq & ru & 11 & اللغة العربية \\
\hline 11 & v & $\varepsilon$ & - & - & - & 11 & v & $\varepsilon$ & اللغة الإنجليزية \\
\hline 70 & $\leq 7$ & 19 & $\leqslant r$ & $r \varepsilon$ & 11 & rr & rr & 1 & التزبوي والإرة \\
\hline IVY & IrA & $\varepsilon 9$ & $\varepsilon r$ & $r \varepsilon$ & 11 & 1ro & $1 . \varepsilon$ & $r_{1}$ & المجموع \\
\hline
\end{tabular}

يتضح من بيانات الجدول (1) أن إجمالي مجتمع البحث بلغ

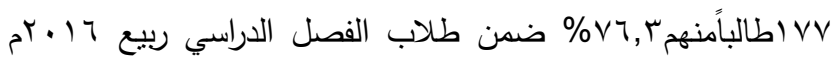

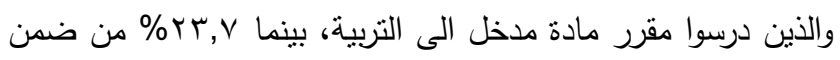
طلاب فصل الخريف VI I.rم ممن درسوا مقرر علم السكان خلال

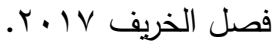

أما من حيث نوزيع مجتمع الدراسة بين الذكور والإناث فقد

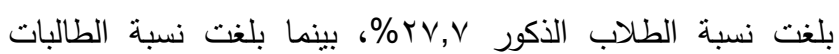

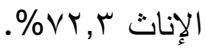

ومن حيث توزيع مجتمع الدراسة على الأقسام العلمية فقد بلغت

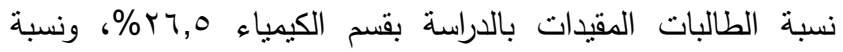

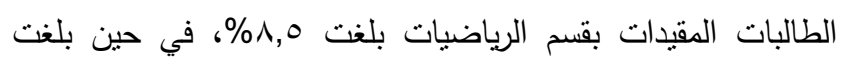
نسبتهن بقسم اللغة العربية rr\%، أما طالبات قسم اللغة الانجليزية فقد بلغت نسبتهن r, ٪\%، وبلغت نسبة طالبات قسم الإدارة والتخطيط

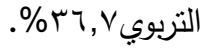

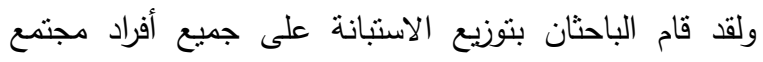

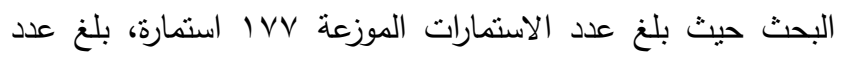
الاستمارات المسترجعة إيا استمارة، وبلغ عدد الاستمارات المفقودة بr استمارة، كما بلغ عدد الاستمارات المستبعدة من التحليل

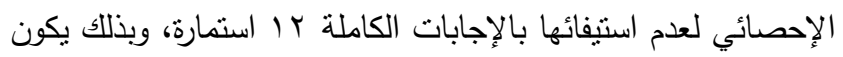

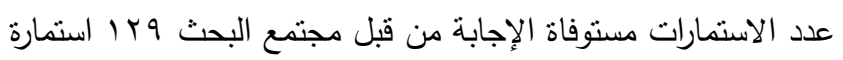

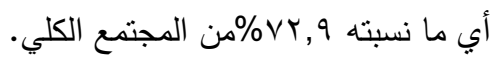

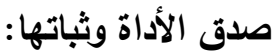

قام الباحثان بإعداد استبانة موجهة لطلاب الكلية بهدف التعرف التهان

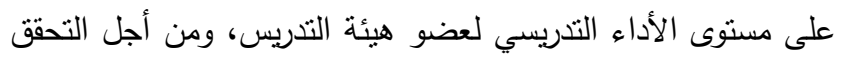

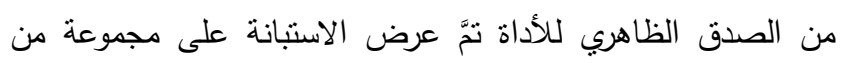
المحكمين بكليتي التربية جامعة سرت ومصراته، ولقد اقترح بعضهم فصل العبارات المركبة، كما اقترح آخرون إضافةَ عبارات جديدة، ونَقْلَ

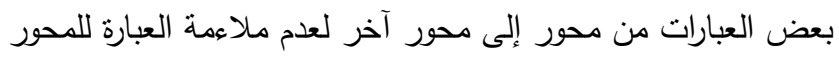

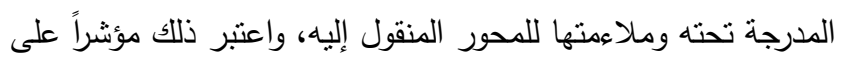

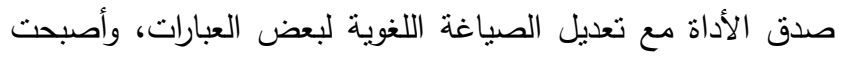

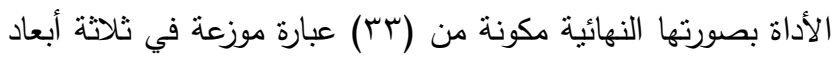

والقرني، علي بن سعد، وآخرون،(ז') هدفت هذه الدراسة إلى بناء أدوات لقياس أداء عضو هيئة التدريس، وبناء قاعدة بيانات تراكمية لتقويم أداء عضو هيئة التدريس في جامعة الملك سعود، وقام

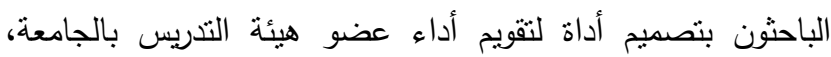
مستعينين في ذللك بالدراسات السابقة، والرجوع إلى البيانات المنوفرة

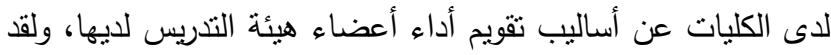

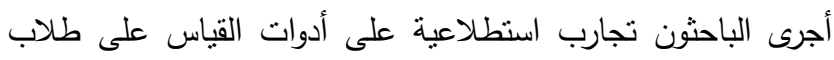

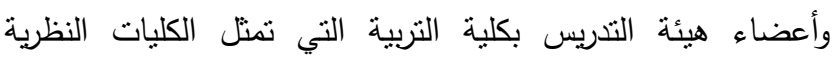
بالجامعة، وكلية الهندسة التي تمثل الكليات التطبيقية للمقررات الدراسية التي يدرسها هؤلاء الأعضاء، وتوصلت الدراسة إلى بناء أداة

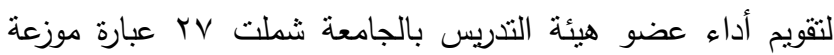
على ستة محاور في ضوء آراء الطلاب بالجامعة.

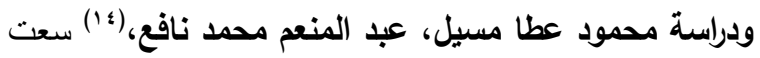
هذه الدراسة إلى الإجابة عن تساؤل رئيسي هو: كيف يمكن نطوير

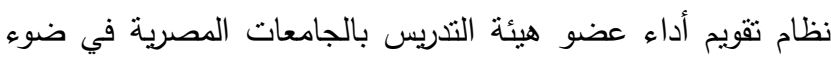

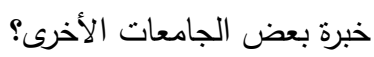
وبناء عليه استهدفت هذه الدراسة بيان أوجه الاتفاق والاختلاف الاخري بين كل من الخبرات الأجنبية وخبرة الجامعات الدصرية في الأبعاد التي تم عرضها لعملية تقويم أداء عضو هيئة التدريس ثم وضع لئرة

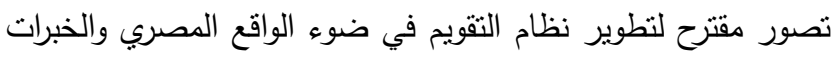

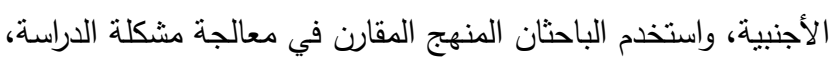

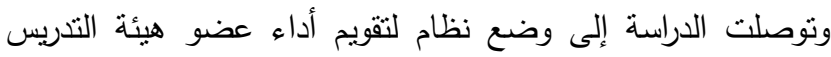
بالجامعات المصرية في ضوء خبرات الولايات المتحدة الأمريكية وبريطانيا. - وبات

\section{الاراسة الميدانية وإجراء|تها:}

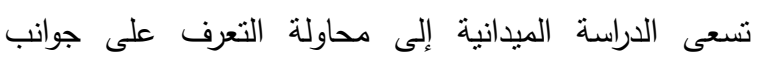
الضعف والقوة في الأداء التنريسي لعضو هيئة التدريس بكلية التربية بجامعة سرت في ليييا من وجهة نظر طلابه، ولقد اتبعت الدراسة

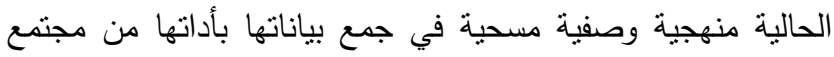
الدراسة وتحليلها، وفيما يلي وصفُ لمجتمع الدراسة:

\section{مجتمع الاراسة:}

تكون مجتمع الدراسة الحالية من جميع طلاب الفصل الدراسي الرابع ربيع 17 •r ممن درسوا مقرر مدخل إلى التربية، والمجموعة

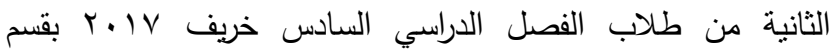
التخطيط والإدارة التربوية ممن درسوا مقرر علم السكان والجدول التالي يوضح ذلك: 
تشير بيانات الجدول (r) أنّ درجات الارتباط بين العبارات

الخاصة بتقويم أداء عضو هيئة الندريس بالكلية من وجهة نظر طلبة

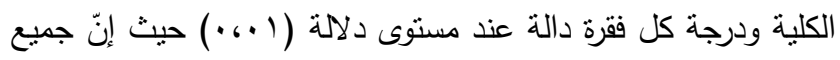

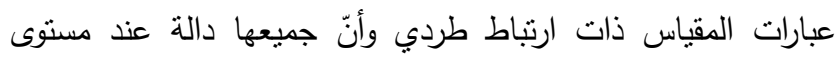
الدلالة ا .، . حيث تراوحت درجات الارتباط ما بين أعلى وأقوى درجة

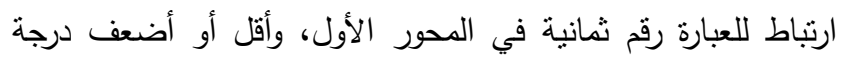

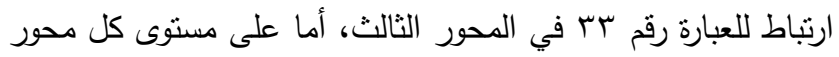

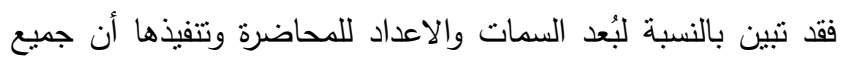

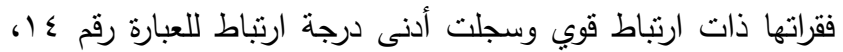
أما بالنسبة لبُعد العلاقات الإنسانية والسمات الثخصية فكانت درجاتها

قوية لكل فقراتها.

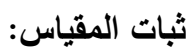

تم حساب معامل الثبات للمقياس باستخدام معامل ألفا كرونباخ، وقد تم بيان ثبات كل محور من محاور المقياس ومن ثم الثبات الكلي

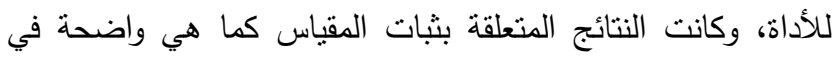

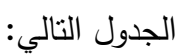

جدول ( ) يوضح درجة الثبات لكل محور من محاور المقياس وللمقياس ككل لتقويم أداء عضو هيئة التريس بالكلية من وجهة نظر طلبة الكلية باستخدام معامل الثبات ألفا كرو نباخ.

\begin{tabular}{|c|c|c|c|}
\hline كرو نباخ الفا & عدد الفقرات & المحور & ر.م \\
\hline. .99. & 10 & محور الإعداد للمحاضرة وتتفيذها & 1 \\
\hline .6900 & 1. & محورالأنشطة والتقويم & $r$ \\
\hline .6977 & $\wedge$ & الإنسانية & r \\
\hline . .9人ץ & r & المقياس ككل & \\
\hline
\end{tabular}

يتبين من بيانات الجدول (ع) أنّ معامل ألفا كرو نباخ للمحاور الثلاثة تراوح ما بين 900، ، و .99،، ب، وبصورة عامة فإن درجة معامل ألفا كرو نباخ لكامل المقياس بلغت بهوج،، • وهي درجة عالية

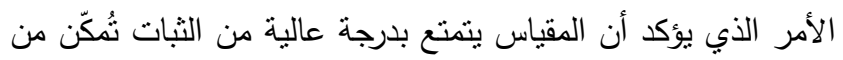
الاعتماد والوثوق من نتائجه في تقويم أداء عضو هيئة التدريس من التركي

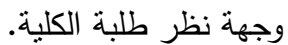

\section{عرض النتائج ومناقشتها:}

يعرض الباحثان فيما يلي للنتائج التي توصلا إلئها: التساؤلات التي تضدنتها مشكلة الدراسة: السؤال الأول: هل هناك فروق ذات دلالة إحصائية بين استجابات الطلاب حول تقويم الأداء تُعزى لجنس الطالب؟ ولتحديد

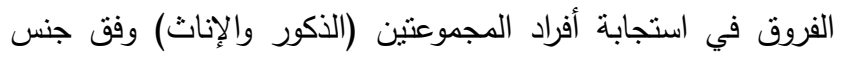
الطالب في تقويم الأداء التدريسي لعضو هيئة التدريس، قام الباحثان باستخدام اختبار ت T-Test للعينات المستقلة وجاءت نتيجة هذا لهاء الاختبار كما هو مبين بالجدول التالي:
منها ما يتعلق بُُعد السمات الثخصية والعلاقات الإنسانية، وبُعد الإعداد للمحاضرة وتتفيذها، وبُعد الأنشطة والتقويم، ونم استخدام تدريج خماسي لمستوى الأداء للاستجابة عن كل فقرة من خمسة الإنة

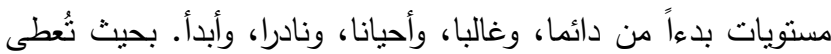
الدرجات (0، ع، ז، ؟، ( ) على التوالي، وعليه تكون أدنى درجة

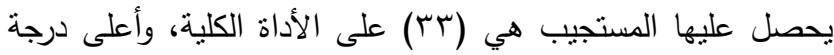
(170)، ولإجابة عن أسئلة البحث، استخدمت الرزمة الإحصائية الإدية

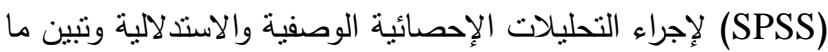
يلي:

الاتساق الاخلي بين المحاور وعبارات الاستبيان: يُعبّر هذا الجانب عن مدى ارتباط كل عبارة من عبارات

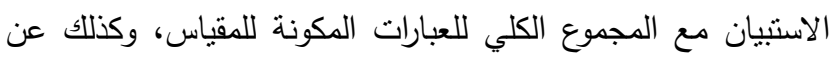
مدى ارتباط كل محور من محاور الاستنيان مع الاستبيان ككل والجدول التالي يبين ارتباط كل محور مع محاور الاستييان ككل.

جدول (ז) يبين درجة ارتباط كل محور من محاور الاستبيان مع الدرجة الكلية

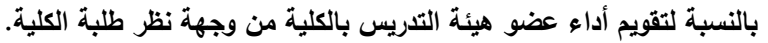

\begin{tabular}{|c|c|c|c|}
\hline مستوى الدلالة & معامل الارتباط & محاور المقياس & ب.ر \\
\hline .. & . ، $\leqslant 7 \leqslant$ & محور السمات الشخصية و العلاقات الإنسانية & 1 \\
\hline. .1 & 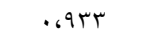 & محور الإعداد للمحاضرة وتتفيذها & r \\
\hline..$\cdot 1$ & . ‘八). & محور الأنشطة والتقويم & r \\
\hline
\end{tabular}

يتضح من بيانات الجدول رقم (r) أن درجات الارتباط بين محاور المقياس والدرجة الكلية له دالة عند مستوى (1 .، •) مما يؤكد على وجود اتساق داخلي وصدق في العوامل التي تحقق هدف

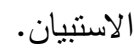
أما من حيث درجة الاتساق الداخلي لكل عبارة من عبارات الاستبيان فالجدول النالي يوضح ذلك: جدول (ॅ) يوضح درجة الاتساق الداخلي لكل عبارة من عبارات تقويم أداء عضو هيئة التدريس من وجهة نظر طلبة الكلية حسب محاورها الرئيسية.

\begin{tabular}{|c|c|c|c|c|c|c|c|}
\hline \multicolumn{2}{|c|}{ محور الأنشطة } & \multicolumn{2}{|c|}{ الثحورالسمات } & \multicolumn{4}{|c|}{ محور الإعداد للمحاضرة وتتفيذها } \\
\hline درجة & رقم & درجة & رقم & درجة & 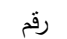 & درجة & رقم \\
\hline الارتباط & 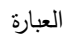 & الازتباط & 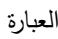 & الارتباط & 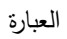 & الارتباط & 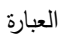 \\
\hline$\cdot$ ‘V人o & $r \leq$ & .69. & 17 &. $.9 T V$ & 11 &. $.9 T V$ & 1 \\
\hline $.6 \vee 09$ & ro & $.69 \times 9$ & iv &. $.9 \vee 7$ & ir &. .941 & r \\
\hline .6799 & דיץ & $\cdot$. $\wedge 9 \leq$ & 11 & $.69 \vee Y$ & ir & $.99 \leqslant$ & r \\
\hline ( & rV & $.691 \varepsilon$ & 19 & .6211 & $1 \varepsilon$ & $.09 \leqslant \leqslant$ & $\varepsilon$ \\
\hline . .95. & rA & $.69 Y \wedge$ & r. & $.694 \wedge$ & 10 & .6907 & 0 \\
\hline .6949 & rq & $.694 \mathrm{~V}$ & r) & & & .9974 & 7 \\
\hline $.69 \leq 7$ & r. & . ‘A०r & rt & & & $.99 \vee 1$ & $\checkmark$ \\
\hline . $995 \leq$ & ו & . „AOr & rT & & &. . $9 \vee r$ & $\wedge$ \\
\hline .6917 & r & & & & & .6907 & 9 \\
\hline אTד . & זr & & & & & $.99 \leq 7$ & 1. \\
\hline
\end{tabular}


جدول (V) يوضح تحديد مستوى الفروق بين الدارسين بالفصل الدراسي الربيع

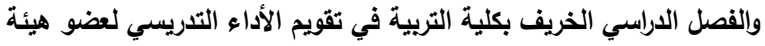

\begin{tabular}{|c|c|c|c|c|c|c|c|}
\hline \multicolumn{8}{|c|}{ التدريس. } \\
\hline مستوى الدلادة & الدلالة & قيمة ت & د.ج & $\varepsilon$ & p & ن & الكلية \\
\hline \multirow{2}{*}{ غير } & \multirow{2}{*}{., .95 } & \multirow{2}{*}{1,798} & \multirow{2}{*}{ ITV } & rq,१ & I.r,ro & $9 \varepsilon$ & الخريف \\
\hline & & & & $r \uparrow, \cdot A$ & $9 r, 11$ & ro & الربيع \\
\hline
\end{tabular}

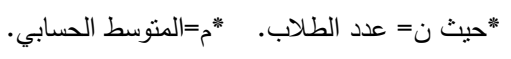

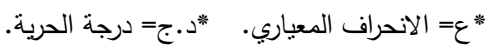

يتضح من بيانات الجدول (V) أن قيمة ت غير دالة إحصائيا

مما بدل على عدم وجود اختلاف ذي دلالة إحصائية في استجابة المجموعتين بالنسبة لتقويم الأداء التدريسي لعضو هيئة التدريس، وأنه

لا يختلف التقويم باختلاف الفصل الدراسي الدارس به الطالب. السؤال الرابع: هل هناك فروق ذات دلالة إحصائية بين استجابات الطلاب حول تقويم الأداء التدريسي لعضو هيئة التدريس تُعزى لمتغير القسم العلمي الدارس با الطالب؟ ولتحديد الفروق في استجابة أفراد عينة الدراسة قام الباحثان باستخدام تحليل التباين أُحادي الاتجاه One Way Anova وذلك لتحديد هل توجد فروق بين استجابات الطلاب باختلاف القسم العلمي

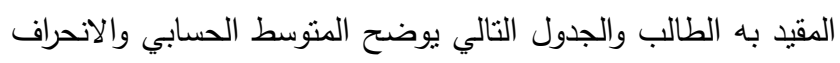

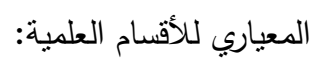

جدول (^) يوضح المتوسطات الحسابية والانحراف المعياري للأقسام العلمية بكلية

\begin{tabular}{|c|c|c|c|}
\hline الانحرافات المعيارية & المتوسطات & العدد & القسم العلمي \\
\hline$\lambda, r \varepsilon$ & $1 r \cdot, \cdot A$ & ro & الكيمياء \\
\hline$\cdot, \cdot$ & $99, \ldots$ & 11 & الرياضيات \\
\hline 0,01 & $7 \lambda, r_{4}$ & זr & اللغة العربية \\
\hline $1 \cdot, \cdot r$ & $v r, q$. & 1. & اللغة الإنجليزية \\
\hline$r V, r$. & 1.1, ro $_{0}$ & $\varepsilon$. & العلوم السلوكية \\
\hline
\end{tabular}

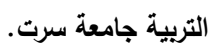

أما عن تحليل التباين في تقويم الأداء التدريسي بين المجموعات أو داخل المجموعات فالجدول التالي يوضح ذلك:

\begin{tabular}{|c|c|c|c|c|c|}
\hline مستوى & قيمة ف & متوسطات المربعات & الحرية & المربعات & مصدر \\
\hline \multirow{3}{*}{ ع علد } & \multirow{3}{*}{$7 \leqslant, q .0$} & $|V \lambda| 7,0 . r$ & $\varepsilon$ & VIrty & المجموعات \\
\hline & & $r V \leqslant, 0 . r$ & ITE & $r \varepsilon \cdot r \wedge, r \vee q$ & المجموعات \\
\hline & & & 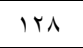 & $1.0 r \cdot \varepsilon, r \wedge \Lambda$ & الإجمالي \\
\hline
\end{tabular}
جدول (9) يوضح تحليل التباين أُحادي الاتجاه بين الاقسام العلمية في تقويم الأداء
جدول (•) يوضح تحديد مستوى الفروق بين الطلاب الذكور والإناث بكلية التربية

\begin{tabular}{|c|c|c|c|c|c|c|c|}
\hline مستوى الدلالة & الدلالة & قيمة & د.ج & $\varepsilon$ & p & $\dot{ن}$ & الاراسية \\
\hline \multirow{2}{*}{ غير دالة } & \multirow{2}{*}{$\cdot, r \leq}$. & \multirow{2}{*}{$1,1 \wedge$. } & \multirow{2}{*}{ IrV } & $r v, 7 q$ & D.r., & ro & الذكور \\
\hline & & & & YA,0T & 97,07 & $9 \leqslant$ & الإناث \\
\hline
\end{tabular}
جامعة سرت في تقويم الأداء التدريسي لعضو هيئة التدريس.

"حيث ن= عدد الطلاب. "ح="المتوسط الحسابي.

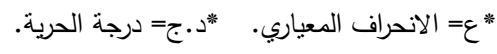

يتضح من بيانات الجدول (0) أن قيمة ت غير دالة إحصائيا مما يدل على عدم وجود اختلاف ذي دلالة إحصائية في استجابة المجموعتين بالنسبة لتقويم الأداء التدريسي لعضو هيئة التدريس، وأنه

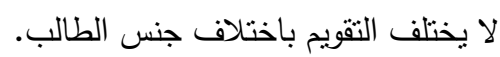
السؤال الثاني: هل هنالك فروق ذات دلالة إحصائية بين استجابات الطلاب حول تقويم الأداء التذريسي لعضو هيئة التدريس

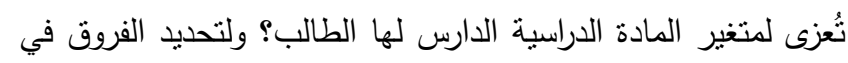
استجابة أفراد المجموعتين الدارسين لمادتي مدخل إلى التربية وعلم السكان وفق المادة الدراسية الدارس لها الطالب في تقويم الأداء التدريسي لعضو هيئة التدريس، قام الباحثان باستخدام اختبار ت TTest

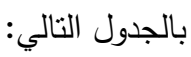

جدول (؟) يوضح تحديد مستوى الفروق بين الارسبين لمادة مدخل إلى التربية

\begin{tabular}{|c|c|c|c|c|c|c|c|}
\hline مستوى & الدلالة & قيمة ت & د.ج & $\varepsilon$ & p & ن & الدراسي \\
\hline \multirow[t]{2}{*}{ غير دالة } & \multirow[t]{2}{*}{ ז4 1, • } & \multirow[t]{2}{*}{$1, \varepsilon \cdot \varepsilon$} & \multirow[t]{2}{*}{ ITV } & $r \wedge, \wedge q$ & 97,11 & $9 \leq$ & مدخل إلى \\
\hline & & & & $r v, V I$ & $1 . \leqslant, .0$ & ro & علم السكان \\
\hline
\end{tabular}

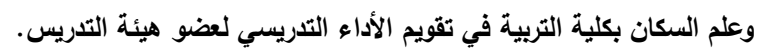

"حيث ن= عدد الطلاب. "م=المتوسط الحسابي.

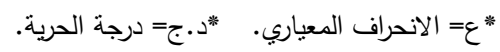

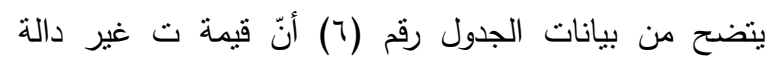
إحصائيا مما بدل على عدم وجود اختلاف ذي دلالة إحصائية في استجابة المجموعتين بالنسبة لتقويم الأداء التدريسي لعضو هيئة التدريس، وأنه لا يختلف التقويم باختلاف المادة الدراسية. السؤال الثالث: هل هناك فروق ذات دلالة إحصائية بين استجابات الطلاب حول تقويم الاداء التدربسي لعضو هيئة التدريس تُعزى لمتغير الفصل الدراسي المقيد به الطالب ؟ ولتحديد الفروق في استجابة أفراد المجموعتين من الطلاب المقيدين بالدراسة بالفصل

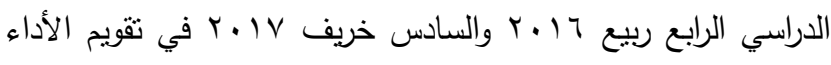
التدريسي لعضو هيئة التدريس، قام الباحثان باستخدام اختبار ت-T-T Test للعينات المستقلة وجاءت نتيجة هذا الاختبار كما هو مبين بالجدول التالي: 
بتضح من بيانات الجدول (1) والمتعلق بنتائج التحليل الإحصائي باستجابات الطلاب حسب الأقسام العلمية حول تقويم الأداء لعضو هيئة الندريس في جانب التخطيط والإعداد للمحاضرة والقائها حيث جاءت على النحو الآتي: أنَّ هناك فروقاً ذات دلالة إحصائية حيث كانت قيمة كا لاتئ المحسوبة أكبر من قيمة كا الجدولية حول بعض بنود مقياس تقويم

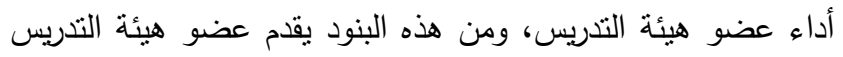
أهداف دراسة المقرر عند بداية دراسة المقرر، ويقدم عضو هيئة التدريس في بداية تدريسه وصفاً لموضوعات الدقرر ومنطلبات دراسته، ويعرض عضو هيئة التدريس المادة بأسلوب يسهل على الطالب فهمها، وعن مدى امتلاك عضو هيئة التدريس مقدرة للربط والنسلسل في نقل الأفكار، وعن مدى إعداد وتجهيز عضو هئن هيئة التنريس نفسه لنقديم الدحاضرة، وعن مدى وضوح صوته، وقدرته على ضبط المحاضرة، دون انفعال وحَزمه في إدارة القاعة الدراسية فقد وجدت فروقاً ذات دلالة احصائية بين الاقسام العلمية بالكلية

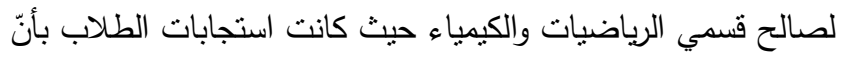

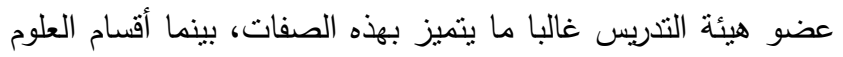
الإنسانية افادت بأنه نادراً وقليلا ما نوجد هذه الصفات في عضو لفئ هيئة

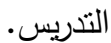
كذلك وجدت فروق ذات دلالة إحصائية لأقسام علمية وفروق

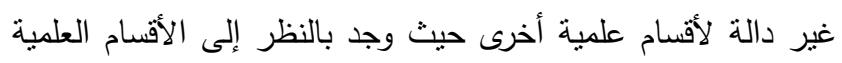
الكيمياء والرياضيات أنه ذو دلالة باعتبار أن قيمة كا المحسوبة كانت أكثر من قيمة كا الجدولية عند مستوى ا..,· في عبارات التقويم

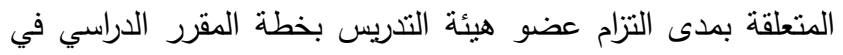

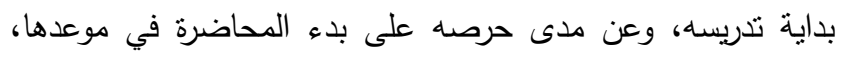
ومدى إلمامه بالمادة العلمية التي يقوم بتدريسها، أما بالنسبة للأقسام

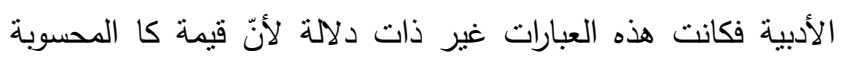

$$
\text { أقل من قيمة كا الجدولية. }
$$

كما أنّ هنالك اتفاقاً بين الأقسام العلمية حيث كانت قيمة كا

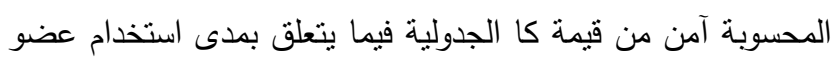
هيئة التدريس للوسائل التعليمية، وهل يربط عضو هيئة التدريس بين ما نم تعليميه وبين ما يطبق بالحياة. ثانيا: تقويم الأداء التدريسي لعضو هيئة التدريس من جانب بلباء

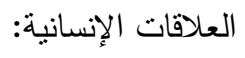

بتحليل بيانات بطاقة نقويم الأداء التكريسي في بُعدها المنعلق بالعلاقات الإنسانية، ولتحديد وجه الاختلاف في الفروق قام الباحثان

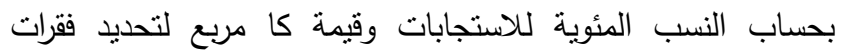
التقويم التي لاقت اختلافا في الاستجابات من قبل الطلاب ويوضحها

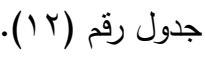

تشير بيانات الجدول (9) أنّ هناك فروقاً ذات دلالة إحصائية

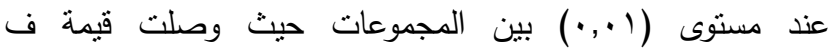

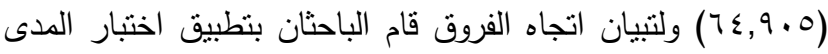
المتعدد لتوكي (Tukey) لتحديد مصدر واتجاه الفروق الدالة بين متوسطات المجموعات ويوضحها الجدول النالي: جدول رقم ( • 1) نتائج اختبار توكي (الفرق بين المتوسطات ودلالة الفروق) لتحديد

\begin{tabular}{|c|c|c|c|c|}
\hline اللغة الانجليزية & اللغة العربية & الرياضيات & الكيمياء & القسم العلمي \\
\hline & & ----------- & *T, & الرياضيات \\
\hline & --------- & - & *I, VYYI- & اللغة العربية \\
\hline ------ & 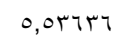 & $* Y 0,1 \ldots-$ & $\% 04,110 \mathrm{~V}-$ & اللغة الإنجليزية \\
\hline$* Y V, \leq 0 \ldots$ & דזT, & $r, r o \ldots$ & $* \curlyvee \Lambda, \vee T O Y-$ & التخطيط \\
\hline
\end{tabular}
اتجاه الفروق في الاستجابات بين المجموعات.

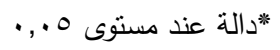

تشيبر بيانات الجدول (• (1) أنّ هناك فروقاً ذات دلالة إحصائية

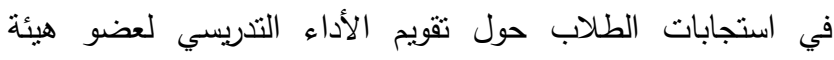
التدريس عند مستوى (0. . •) بين تقويم طلاب قسم الكيمياء وطلاب قسم الرياضيات لصالح طلاب قسم الكيمياء، وبين طلاب قسم اللغة العربية وطلاب قسم الكيمياء لصالح طلاب قسم الكيمياء، وبين طلاب

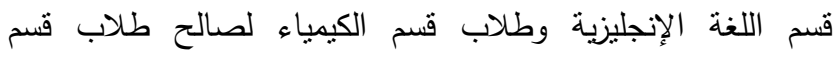
الكيمياء، وبين الطلاب بقسم الإدارة والتخطيط وطلاب قسم الكيمياء لصالح طلاب قسم الكيمباء. وبين طلاب قسم الرياضيات وطلاب قسم اللغة العربية لصالح طلاب قسم الرياضيات، وبين طلاب قسم الرياضيات وطلاب قسم

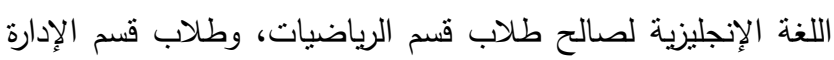
والتخطيط وطلاب قسم اللغة العربية لصالح طلاب الإدارة والتخطيط، وبين طلاب قسم الادارة والتخطيط وطلاب قسم اللغة الإنجليزية لصالح طلاب قسم الإدارة والتخطيط، ولا توجد دلالة بين باقي

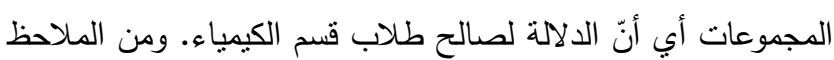

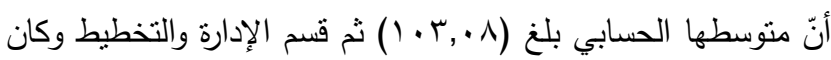
منوسطها الحسابي (0., 1 • (1). ونظرا لوجود فروق ذات دلالة إحصائية وفقا للأقسام العلمية يعرض الباحثان فيما يلي لجوانب التقويم وفقا لأبعادها الثناثة:

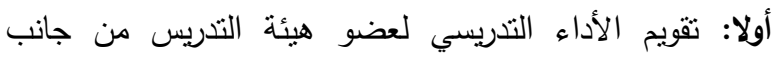
التخطيط والإعداد للمحاضرة وتتفيذها:

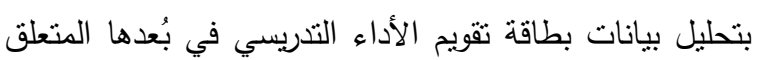

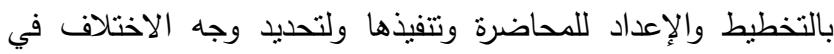
الفروق، قام الباحثان بحساب النسب المئوية للاستجابات وقيمة كا مربع لتحديد فقرات التقويم التي لاقت اختلافا في الاستجابات من قبل الطلاب ويوضحها جدول رقم (1'). 
جدول (1 1) يوضح استجابات تقويم الأداء التدريسي لعضو هيئة التدريس في بعد التخطيط والإعداد للمحاضرة كأحد جوانب التقويم والفروق في الاستجابات حب الأقسام العلمية.

\begin{tabular}{|c|c|c|c|c|c|c|c|c|c|}
\hline \multirow[t]{2}{*}{ الدلائة } & \multirow[t]{2}{*}{ قيمة كا } & \multicolumn{5}{|c|}{ نوع الاستجابة } & \multirow{2}{*}{ والتسبة } & \multirow{2}{*}{ الاقسام العلمية } & \multirow{2}{*}{ بنود المقياس } \\
\hline & & دائما & غالبا & احيانا & قليلا & نادرا & & & \\
\hline \multirow{10}{*}{ دالة عند مستوى } & \multirow{10}{*}{$r \cdot \varepsilon, \wedge r T$} & . & r & $r$ & . & . & ك5 & \multirow{2}{*}{ الكيمياء } & \multirow{10}{*}{ عقدم عضو هيئة التدريس البدء في تدريس المقرر أهداف دراسة } \\
\hline & & $\cdot, \cdots$ & $q \leq, r q$ & $0, V_{1}$ & & $\cdot, \cdots$ & $\%$ & & \\
\hline & & . & . & 11 & . & . & ك & \multirow{2}{*}{ الرياضيات } & \\
\hline & & $\cdot, \cdots$ & $\cdot, \cdots$ & $1 \ldots$ & $\cdot, \cdots$ & $\cdot, \cdots$ & $\%$ & & \\
\hline & & . & . & . & rt & V & ك & \multirow{2}{*}{ اللغة العربية } & \\
\hline & & $\cdot, \cdots$ & $\cdot, \cdots$ & $\cdot, \cdots$ & $\vee \wedge \wedge, \vee q$ & 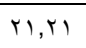 & $\%$ & & \\
\hline & & . & . & 1 & $r$ & V & 5 & \multirow{2}{*}{ اللغة الإنجليزية } & \\
\hline & & $\cdot, \cdots$ & $\cdot, \cdots$ & $1, \ldots$ & $r \cdot, \ldots$ & $v \cdot, \ldots$ & $\%$ & & \\
\hline & & 7 & it & $r$ & 10 & $\varepsilon$ & 5 & \multirow{2}{*}{ الإدارة والتخطبط } & \\
\hline & & $10, \ldots$ & $r \cdot, \ldots$ & $\vee, 0$. & $r v, 0$. & $1,, \ldots$ & $\%$ & & \\
\hline \multirow{10}{*}{ دالة عند مستوى } & \multirow{10}{*}{194,111} & . & r & $r$ & . & . & 5 & \multirow{2}{*}{ الكيمباء } & \multirow{10}{*}{ في بلدم عضو هيئة التدريس تدريسه وصفا } \\
\hline & & $\cdot, \cdots$ & $q \leq, r q$ & $0, V_{1}$ & $\cdots$ & $\cdot, \cdots$ & $\%$ & & \\
\hline & & . & . & 11 & . & . & 5 & & \\
\hline & & $\cdot, \cdots$ & $\cdot, \cdots$ & $1 \cdots$ & $\cdot, \cdots$ & $\cdot, \cdots$ & $\%$ & الرياضيات & \\
\hline & & . & . & . & ru & v & ك & $\therefore \quad 4 \%$ & \\
\hline & & $\cdot, \cdots$ & $\cdot, \cdots$ & $\cdot, \cdots$ & $\vee \wedge, \vee q$ & $r \mid, Y M$ & $\%$ & اللعه العربيه & \\
\hline & & . & . & . & $r$ & V & ك & & \\
\hline & & $\cdot, \cdots$ & $\cdot, \cdots$ & $\cdot, \cdots$ & $r \cdot, \cdots$ & $v_{\cdot,}, \cdots$ & $\%$ & اللغة الإنجليزية & \\
\hline & & $r$ & 9 & 0 & IV & 7 & ك & $1, \cdots+\cdots$ & \\
\hline & & $v, 0$ & rr,O. & $1,0$. & $\varepsilon r, 0$. & $10, \ldots$ & $\%$ & الإدارة والنحطيط & \\
\hline \multirow{5}{*}{ دالة عند مستوى } & & . & r & $r$ & . & . & ك & 1811 & \\
\hline & it & $\cdot, \cdots$ & $q \leq, Y q$ & $0, V_{1}$ & $\cdots$ & $\cdot, \cdots$ & $\%$ & الكيمياء & \\
\hline & $M \cdot, \pi$ & . & . & 11 & . & . & ك & & \\
\hline & & $\cdot, \cdots$ & $\cdot, \cdots$ & $1 \cdots$ & $\cdot, \cdots$ & $\cdot, \cdots$ & $\%$ & الرياضبات & \\
\hline & & · & . & . & ry & V & ك & & يلتزم عضو هيئة التدريس \\
\hline & & $\cdot, \cdots$ & $\cdot, \cdots$ & $\cdot, \cdots$ & $\vee \wedge, \vee \vee q$ & 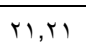 & $\%$ & اللغة العربية & بخطة المقرر المتفق عليها \\
\hline & & . & . & . & r & v & ك & & في بدايه العام الدراسي \\
\hline غير دالة عند مستوى & $\Lambda \cdot, l r$ & $\cdot, \cdots$ & $\cdot, \cdots$ & $\cdot, \cdots$ & $r \cdot, \ldots$ & $v_{\cdot,}, \ldots$ & $\%$ & اللغة الإنجليزية & \\
\hline & & $r$ & $1 \leq$ & $r$ & 10 & 7 & ك5 & & \\
\hline & & $v, 0$. & $r_{0, \ldots}$ & $0, \ldots$ & $r v, 0$. & $10, \ldots$ & $\%$ & الإدارة والتخطبط & \\
\hline & & . & r & r & . & . & 5 & & \\
\hline$\cdot, \cdot 1$ & Ir $\varepsilon, 1 Y$ & $\cdot, \cdots$ & $q \leq, r q$ & $0, V_{1}$ & & $\cdot, \cdots$ & $\%$ & الكيمياء & \\
\hline دالة عند مسنوى & & . & . & 11 & . & . & 5 & & \\
\hline & & $\cdot, \cdots$ & $\cdot, \cdots$ & $1 \cdots$ & $\cdot, \cdots$ & $\cdot, \cdots$ & $\%$ & الرياضبات & يحرص عضو هيئة \\
\hline & & . & . & . & rt & v & 5 & & التدريس على بدء \\
\hline & & $\cdot, \cdots$ & $\cdot, \cdots$ & $\cdot, \cdots$ & $\vee \wedge, \vee q$ & YI,Y & $\%$ & اللغة العربية & المحاضرة وإنهائها في \\
\hline غير دالة عند مستوى & ar $1 \leqslant$ & . & . & . & $r$ & $\mathrm{v}$ & 5) & 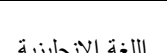 & موعدها . مو \\
\hline., .0 & $\lambda T, 1 \varepsilon$ & $\cdot, \cdots$ & $\cdot, \cdots$ & $\cdot, \cdots$ & $r \cdot, \cdots$ & $v \cdot, \cdots$ & $\%$ & اللغه الإنجليزيه & \\
\hline & & $r$ & $\wedge$ & $r$ & 17 & 1. & 5 & 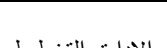 & \\
\hline & & $v, 0$ & $r \cdot, \ldots$ & $v, 0$ & $\varepsilon \cdot, \cdots$ & $r_{0, \ldots}$ & $\%$ & الإدارة والتخطيط & \\
\hline & & . & r & $r$ & . & . & 5 & 10 & \\
\hline & & $\cdot, \cdots$ & $q \leq, r q$ & $0, V_{1}$ & $\cdots$ & $\cdot, \cdots$ & $\%$ & الكيمياء & \\
\hline & & . & . & 11 & . & . & ك & & \\
\hline دالة عند مستوى & $r \times 107$ & $\cdot, \cdots$ & $\cdot, \cdots$ & $1 \cdots$ & $\cdot, \cdots$ & $\cdot, \cdots$ & $\%$ & الرياضيات & يعرض عضو هيئة \\
\hline$\cdot,+1$ & $1 \cdot v, 707$ & · & . & . & $r y$ & v & 5 & ت" & التخريس المادة باسلوب \\
\hline & & $\cdot, \cdots$ & $\cdot, \cdot$ & $\cdot, \cdots$ & $\vee \wedge, \vee q$ & $r \mid, Y$ & $\%$ & اللغة العربية & يسـهل عليك \\
\hline & & . & . & . & $r$ & V & ك & & \\
\hline & & $\cdot, \cdots$ & $\cdot, \cdots$ & $\cdot, \cdots$ & $r \cdot, \ldots$ & $v \cdot, \ldots$ & $\%$ & اللغة الإنجليزية & \\
\hline
\end{tabular}


المجلة الدولية لضمان الجودة - المجلد الثاني - العدد الثاني، 9 ـ ؟r.

\begin{tabular}{|c|c|c|c|c|c|c|c|c|c|}
\hline \multirow[t]{2}{*}{ الدلالة } & \multirow[t]{2}{*}{ قيمة كا } & \multicolumn{5}{|c|}{ نوع الاستجابة } & \multirow{2}{*}{ والتسبرار } & \multirow{2}{*}{ الاقسام العلمية } & \multirow{2}{*}{ بنود المقياس } \\
\hline & & دائما & غالبا & احيانا & قليلا & ن ل & & & \\
\hline & & $\varepsilon$ & 1. & r & 17 & $\wedge$ & ك5 & & \\
\hline & & $1 \cdot, \cdots$ & ro, . & $0, \cdots$ & $\varepsilon \cdot, \cdots$ & $r \cdot, \cdots$ & $\%$ & الإداره والنحطيط & \\
\hline \multirow{10}{*}{ دالة عند مستوى } & \multirow{10}{*}{$r \mid r, q \wedge)$} & . & זr & r & . & . & ك & \multirow[b]{2}{*}{ الكيمياء } & \multirow{10}{*}{ مقدرة على الربط والتسلسل هيئة التدريس } \\
\hline & & $\cdot, \cdots$ & $9 \leq, Y q$ & $0, \times 1$ & $\cdots$ & $\cdot, \cdots$ & $\%$ & & \\
\hline & & . & . & 11 & . & . & ك & \multirow{2}{*}{ الرياضيات } & \\
\hline & & $\cdot, \cdots$ & $\cdot, \cdots$ & $1 \ldots$ & $\cdot, \cdots$ & $\cdot, \cdots$ & $\%$ & & \\
\hline & & . & . & . & ry & V & ك & \multirow{2}{*}{ اللغة العربية } & \\
\hline & & $\cdot, \cdots$ & $\cdot, \cdots$ & $\cdot, \cdots$ & $\vee \wedge, \vee q$ & $Y_{1, Y M}$ & $\%$ & & \\
\hline & & . & . & . & $r$ & V & 5 & \multirow{2}{*}{ اللغة الإنجليزية } & \\
\hline & & $\cdot, \cdots$ & $\cdot, \cdots$ & $\cdot, \cdots$ & $r \cdot, \cdots$ & $v \cdot, \cdots$ & $\%$ & & \\
\hline & & $r$ & $1 \leq$ & $r$ & 10 & 4 & 5 & 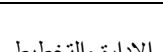 & \\
\hline & & $\mathrm{V}, \mathrm{O}$ & $r_{0}, \ldots$ & $0, \ldots$ & $r v, 0$. & $10, \ldots$ & $\%$ & الإداره والنحطيط & \\
\hline \multirow{4}{*}{ دالة عند مستوى } & \multirow{4}{*}{ ITY,IY } & . & rr & $r$ & . & $\cdot$ & ك & \multirow{2}{*}{ الكيمياء } & \multirow{10}{*}{ بالمّم عضو هيئة التدريس } \\
\hline & & $\cdot, \cdots$ & $q \leq, Y q$ & $0, \times 1$ & $\cdots$ & $\cdot, \cdots$ & $\%$ & & \\
\hline & & . & . & 11 & . & $\cdot$ & 5 & & \\
\hline & & $\cdot, \cdots$ & $\cdot, \cdots$ & $1 \ldots$ & $\cdot, \cdots$ & $\cdot, \cdots$ & $\%$ & الرياصبات & \\
\hline \multirow{6}{*}{ غير دالة عند مستوى } & & . & . & . & rt & V & S & اللغة العبنة & \\
\hline & & $\cdot, \cdots$ & $\cdot, \cdots$ & $\cdot, \cdots$ & $\vee \wedge, \vee q$ & YI, Y & $\%$ & اسمس السربي. & \\
\hline & $x<1$ & . & $\cdot$ & . & 1 & 9 & 5 & & \\
\hline & $\sqrt{2, \lambda}$ & $\cdot, \cdots$ & $\cdot, \cdots$ & $\cdot, \cdots$ & $1 \cdot, \cdots$ & $9 \cdot, \cdots$ & $\%$ & السعه الإنجليرية & \\
\hline & & r & 1. & r & 17 & 9 & 5 & & \\
\hline & & $0, \ldots$ & ro,.. & $\mathrm{v}, \mathrm{O}$ & $\varepsilon \cdot, \cdots$ & rr,o. & $\%$ & الإدارة والنخطيط & \\
\hline & & . & r & r & $\cdot$ & . & ك & & \\
\hline & & $\cdot, \cdots$ & $9 \leq, Y q$ & $0, \times 1$ & $\cdots$ & $\cdot, \cdots$ & $\%$ & الحيمياء & \\
\hline & & . & . & 11 & . & . & ك & & \\
\hline & & $\cdot, \cdots$ & $\cdot, \cdots$ & $1 \ldots$ & $\cdot, \cdots$ & $\cdot, \cdots$ & $\%$ & الرياصيات & \\
\hline دالة عند مستوى & ryta & . & . & . & rt & V & 5 & 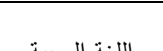 & يعد عضو هيئه التذريس \\
\hline$\cdot, \cdot 1$ & $111,7 \cdot 2$ & $\cdot, \cdots$ & $\cdot, \cdots$ & $\cdot, \cdots$ & $\vee \wedge, \vee q$ & $r, r_{1}$ & $\%$ & اللعه العربيه & لقسه إعداد ناما للفيم \\
\hline & & $\cdot$ & . & . & 1 & 9 & 5 & & 10 \\
\hline & & $\cdot, \cdots$ & $\cdot, \cdots$ & $\cdot, \cdots$ & $1 \cdot, \cdots$ & $9 \cdot, \cdots$ & $\%$ & اللعه الإبجليريه & \\
\hline & & $\circ$ & 7 & $\circ$ & 19 & $\circ$ & 5 & b har & \\
\hline & & $1 Y, 0$. & $10, \ldots$ & $1 r_{6} 0$ & $\varepsilon \vee, 0$ & 1,0 & $\%$ & الإداره والاحطيط & \\
\hline & & $\cdot$ & $\cdot$ & $\cdot$ & 9 & זי & ك & لالكيn & \\
\hline & & $\cdot, \cdots$ & $\cdot, \cdots$ & $\cdot, \cdots$ & rO,VY & $V \leqslant, Y \wedge$ & $\%$ & الحيمياء & \\
\hline & & $\cdot$ & $\cdot$ & 11 & . & . & ك & .1 .1 & \\
\hline & & $\cdot, \cdots$ & $\cdot, \cdots$ & $1 \cdots$ & $\cdot, \cdots$ & $\cdot, \cdots$ & $\%$ & الرياصبات & \\
\hline غير دالة عند مستوى & $V_{7}$ & . & . & . & v & rt & 5 & الاتية & يعتمد عضو هيئه التذريس \\
\hline$\cdot, \cdot 1$ & & $\cdot, \cdots$ & $\cdot, \cdots$ & $\cdot, \cdots$ & $Y_{1, Y}$ & $\vee \wedge, \vee q$ & $\%$ & اللعه العربيه & على احلر من مرجع في \\
\hline & & . & . & 9 & 1 & - & ك & الازة لVان. & \\
\hline & & $\cdot, \cdots$ & $\cdot, \cdots$ & $9 \cdot, \cdots$ & $1 \cdot, \cdots$ & $\cdot, \cdots$ & $\%$ & السعه الإججليريه & \\
\hline & & 。 & 11 & . & r & 10 & ك & . & \\
\hline & & ir,o. & $\leqslant 0, \ldots$ & $\cdot, \cdots$ & $\wedge$, & rr,o. & $\%$ & الإدارة والنحطيط & \\
\hline & & . & rt & r & . & . & ك & & \\
\hline & & $\cdot, \cdots$ & $q \leq, Y q$ & $0, \times 1$ & $\cdots$ & $\cdot, \cdots$ & $\%$ & يمياء - يمي & \\
\hline & & . & $\cdot$ & 11 & . & . & 5 & . & \\
\hline دالة عند مستوى & r. & $\cdot, \cdots$ & $\cdot, \cdots$ & $1 \ldots$ & $\cdot, \cdots$ & $\cdot, \cdots$ & $\%$ & الرياصيات & ينحدت عضو هينه \\
\hline$\cdot, \cdot 1$ & רות & . & $\cdot$ & . & rt & v & ك & ة & \\
\hline & & $\cdot, \cdots$ & $\cdot, \cdots$ & $\cdot, \cdots$ & $\vee \wedge, \vee q$ & $\left(Y, r_{1}\right.$ & $\%$ & اللعه العربية & 3 \\
\hline & & . & . & . & 1 & 9 & ك & & \\
\hline & & $\cdot, \cdots$ & $\cdot, \cdots$ & $\cdot, \cdots$ & $1 \cdot, \cdots$ & $q \cdot, \ldots$ & $\%$ & اللغه الإنجليزيه & \\
\hline
\end{tabular}


تقويم الأداء التدريسي لعضو هيئة التدريس بكلية التربية جامعة سرت في ليبيا من وجهة نظر طلبة الكلية كمخل لتحقيق جودة التعليم الجامعي.

\begin{tabular}{|c|c|c|c|c|c|c|c|c|c|}
\hline \multirow[t]{2}{*}{ الدلالة } & \multirow[t]{2}{*}{ قيمة كا } & \multicolumn{5}{|c|}{ نوع الاستجابة } & \multirow{2}{*}{ والنكبة } & \multirow{2}{*}{ الاقسام العلمية } & \multirow{2}{*}{ بنود المقياس } \\
\hline & & دائما & غالبا & احيانا & قليلا & 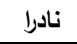 & & & \\
\hline & & $\wedge$ & 9 & $\varepsilon$ & 10 & $\varepsilon$ & s & \multirow{2}{*}{ الإدارة والتخطبط } & \\
\hline & & r.... & rr,O. & $1 \cdot, \ldots$ & $r v, 0$. & $1 \cdot, \cdot$. & $\%$ & & \\
\hline \multirow{10}{*}{ دالة عند مستوى } & \multirow{10}{*}{ rro, $\{7 T$} & . & re & r & . & . & s & \multirow{2}{*}{ الكيمياء } & \multirow{10}{*}{ بيتميز عضو هيئة التدريس في ضيط المحاضرة } \\
\hline & & $\cdot, \cdot$ & $q \leq, Y q$ & $0, V_{1}$ & $\cdots$ & $\cdot, \cdots$ & $\%$ & & \\
\hline & & . & . & 11 & . & . & s & \multirow{2}{*}{ الرياضيات } & \\
\hline & & $\cdot, \cdots$ & $\cdot, \cdot$ & $1 \cdots$ & $\cdot, \cdots$ & $\cdot, \cdots$ & $\%$ & & \\
\hline & & . & . & . & rY & v & ك & & \\
\hline & & $\cdot, \cdot$ & $\cdot, \cdot$ & $\cdot, \cdot$ & $\mathrm{V \wedge}, \mathrm{\vee q}$ & $r, r$, & $\%$ & اللعه العربيه & \\
\hline & & . & . & . & 1 & 9 & s & & \\
\hline & & $\cdot, \cdot$ & $\cdot, \cdot$ & $\cdot, \cdot$ & $1 \cdot, \ldots$ & $9 \cdot, \ldots$ & $\%$ & اللغه الإنجليزية & \\
\hline & & 7 & it & r & $1 \leqslant$ & $\varepsilon$ & ك & 1 & \\
\hline & & $10, \ldots$ & rr,O. & $\mathrm{v}, \mathrm{O}$. & $r_{0}, \ldots$ & $1 \cdot, \ldots$ & $\%$ & الإداره والسحطيط & \\
\hline غير دالة عند مستوى & $v v, 1 \leq$ & . & . & . & $\varepsilon$ & $r$ & 5 & الكيمياء & ينتح عضو هيئة التنريس \\
\hline$\cdot, \cdot 1$ & & $\cdot, \cdot$ & $\cdot, \cdot \cdot$ & $\cdot, \cdot$ & $11, \varepsilon r$ & AN,OV & $\%$ & & الفرصة للنقاش و الحوار في \\
\hline & & . & . & 11 & . & . & s & الرياضيات & أثثاء المحاضرة \\
\hline & &,$+ \cdots$ & $\cdot, \cdots$ & $1 \cdots$ & $\cdot, \cdot$ & $\cdot, \cdots$ & $\%$ & & \\
\hline & & . & 14 & $r$. & . & . & 5 & اللغة العربية & \\
\hline & & $\cdot, \cdots$ & rq, $\leqslant$. & $7 \cdot, 7$ & $\cdot, \cdots$ & $\cdot, \cdots$ & $\%$ & & \\
\hline & & . & . & . & $r$ & $\wedge$ & ك & اللغة الإنجليزية & \\
\hline & & $\cdot, \cdot$ & $\cdot, \cdot \cdot$ & $\cdot, \cdot \cdot$ & $r_{\cdot}, \cdot \cdot$ & $A_{\cdot}, \cdot \cdot$ & $\%$ & & \\
\hline & & 0 & 0 & $\varepsilon$ & $r$. & 7 & s & الإدارة والتخطيط & \\
\hline & & $1,0$. & IT,O. & $1 \cdot, \cdots$ & $0 ., \cdots$ & $10, \ldots$ & $\%$ & & \\
\hline دالة عند مستوى & rrד,rq & . & r & $r$ & . & $\cdot$ & S & الكيمياء & يجيب عضو هيئة التدريس \\
\hline$\cdot, \cdot 1$ & & $\cdot, \cdots$ & $9 \leq, Y 9$ & $0, V_{1}$ & $\cdots$ & $\cdot, \cdots$ & $\%$ & & على أسئلة الطالبات بشكل \\
\hline & & . & . & 11 & . & . & s & الرياضيات & دقيق و واضح. \\
\hline & & $\cdot, \cdots$ & $\cdot, \cdots$ & $1 \cdots$ & $\cdot, \cdots$ & $\cdot, \cdots$ & $\%$ & & \\
\hline & & $\cdot$ & $\cdot$ & $\cdot$ & ry & $\mathrm{v}$ & ك & اللغة العربية & \\
\hline & & $\cdot, \cdots$ & $\cdot, \cdots$ & $\cdot, \cdots$ & $\vee \wedge, \vee 9$ & $r, r_{1}$ & $\%$ & & \\
\hline & & $\cdot$ &. & . & 1 & 9 & s] & اللغة الإنجليزية & \\
\hline & & $\cdot, \cdots$ & $\cdot, \cdots$ & $\cdot, \cdots$ & $1 \cdot, \cdots$ & $9 \cdot, \ldots$ & $\%$ & & \\
\hline & & $\circ$ & $\wedge$ & 1 & 19 & $\mathrm{v}$ & s & الإدارة والتخطيط & \\
\hline & & $1 Y, 0$ & $r \cdot, \cdot$. & r.o. & $\leqslant \vee, O$ & iv,o. & $\%$ & & \\
\hline غير دالة عند مستوى & $77, V 7$ & $\cdot$ & . & $r q$ & 7 & $\cdot$ & s & الكيمياء & بستخدم عضو هيئة التنريس \\
\hline$\cdot,+1$ & & $\cdot, \cdots$ & $\cdot, \cdots$ & $\wedge r, \wedge T$ & $\mid V, 1 \leqslant$ & $\therefore, \cdots$ & $\%$ & & وسائل تعليمية معينة في \\
\hline & & $\cdot$ & $\cdot$ & $\cdot$ & 11 & $\cdot$ & 5 & الرياضيات & التدريس \\
\hline & & $\therefore, \cdots$ & $\cdot, \cdots$ & $\cdot, \cdots$ & $1 \ldots$ & $\therefore, \cdots$ & $\%$ & & \\
\hline & & $\cdot$ & $\cdot$ & $\cdot$ & $r v$ & 7 & 5 & اللغة العربية & \\
\hline & & $\cdot, \cdots$ & $\cdot, \cdots$ &,$+ \cdots$ & $\wedge 1, \wedge r$ & 11,11 & $\%$ & & \\
\hline & & 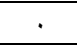 & $\cdot$ & $\cdot$ & 1 & 9 & 5 & اللغة الإنجليزية & \\
\hline & & $\cdot, \cdots$ & $\cdot, \cdots$ & $\cdot, \cdots$ & $1 \cdot, \cdots$ & $9 \cdot, \ldots$ & $\%$ & & \\
\hline & & . & . & $\leqslant$ & ir & $r+$ & S & الإدارة والتخطيط & \\
\hline & & $\cdot, \cdots$ & $\cdot, \cdots$ & $1 \cdot, \cdots$ & rr.o. & ov,o. & $\%$ & & \\
\hline غير دالة عند مستوى & 90,17 & . & ru & r & . & . & s & الكيمياء & يربط عضو هيئة التدريس بين \\
\hline$\cdot, \cdot 1$ & & $\cdot, \cdots$ & $9 \leq, Y 9$ & $0, V_{1}$ & $\cdots$ & $\cdot, \cdots$ & $\%$ & & ما يتم تعلمه وبين ما بطبق في \\
\hline & & . & . & . & 11 & . & 5 & الرياضيات & الحياة العملية . \\
\hline & & $\cdot, \cdots$ & $\cdot, \cdots$ & $\cdot, \cdots$ & $1 \cdots$ & $\cdot, \cdots$ & $\%$ & & \\
\hline & & $\cdot$ & . & . & ru & $\mathrm{v}$ & 5 & اللغة العربية & \\
\hline & & $\cdot, \cdots$ & $\cdot, \cdots$ & $\cdot, \cdots$ & $\vee \wedge, \vee \vee q$ & $r\left(, r_{1}\right.$ & $\%$ & & \\
\hline & & . & . & $\cdot$ & 1 & 9 & 5 & اللغة الانجليزية & \\
\hline & & $\cdot, \cdot$ & $\cdot, \cdot$ & $\cdot, \cdot$ & $1 \cdot, \cdot$. & $9 \cdot, \cdot \cdot$ & $\%$ & & \\
\hline & & $r$ & $r$ & 0 & 19 & 11 & 5 & الادارة والتخطيط & \\
\hline & & $0, \ldots$ & $\mathrm{v}, \mathrm{O}$ & $1 Y, 0$. & $\leqslant v, 0$. & $r v, O$. & $\%$ & & \\
\hline
\end{tabular}


المجلة الدولية لضمان الجودة - المجلد الثاني - العدد الثاني، 9 ـ ـ .

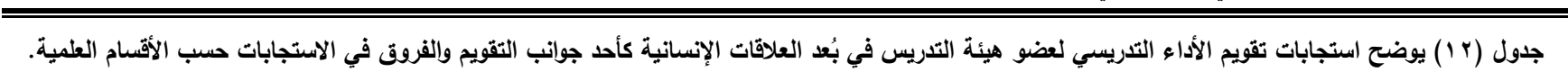

\begin{tabular}{|c|c|c|c|c|c|c|c|c|c|}
\hline \multirow[t]{2}{*}{ الدلالة } & \multirow[t]{2}{*}{ قيمة كا } & \multicolumn{5}{|c|}{ نوع الاستجابة } & \multirow{2}{*}{ والنسبة } & \multirow[t]{2}{*}{ الاقسام العلمية } & \multirow[t]{2}{*}{ بنود المقياس } \\
\hline & & دائما & غالبا & احيانا & قليلا & ن ن ن ادرا & & & \\
\hline \multirow{10}{*}{ دالة عند مسنوى } & \multirow{10}{*}{$1 \leqslant 0, V \vee V$} & . & 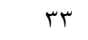 & r & . & $\cdot$ & ك5 & \multirow[t]{2}{*}{ الكيمباء } & \multirow{10}{*}{ التبميز عضو هيئة } \\
\hline & & $\cdot, \cdots$ & $9 \leq, Y q$ & $0, v_{1}$ & & $\cdot, \cdots$ & $\%$ & & \\
\hline & & . & $\cdot$ & 11 & . & $\cdot$ & 5 & \multirow[t]{2}{*}{ الرياضيات } & \\
\hline & & $\cdot, \cdots$ & $\cdot, \cdots$ & $1 \ldots$ & $\cdot, \cdots$ & $\cdot, \cdots$ & $\%$ & & \\
\hline & & . & $\wedge$ & $\cdot$ & ro & . & ك5 & \multirow[t]{2}{*}{ اللغة العربية } & \\
\hline & & $\cdot, \cdots$ & $r \leq, r \leq$ & $\cdot, \cdots$ & $v_{0, V Y}$ & $\cdot, \cdots$ & $\%$ & & \\
\hline & & . & $\wedge$ & 1 & - & 1 & ك5 & \multirow[t]{2}{*}{ اللغة الإنجليزية } & \\
\hline & & $\cdot, \cdots$ & $\Lambda \cdot, \cdots$ & $1 \cdot, \ldots$ & $\cdots$ & $1 \cdot, \ldots$ & $\%$ & & \\
\hline & & r & 11 & $r \cdot$ & $\varepsilon$ & $r$ & ك5 & \multirow[t]{2}{*}{ الإدارة والتخطيط } & \\
\hline & & $0, \ldots$ & $r v, 0$. & $0 ., \ldots$ & $1 \cdot, \ldots$ & $v, 0$. & $\%$ & & \\
\hline \multirow{10}{*}{ دالة عند مستوى } & \multirow[t]{10}{*}{$109,17 \varepsilon$} & 1 & rt & r & · & . & ك5 & \multirow{2}{*}{ الكيمياء } & \multirow{10}{*}{ التدريس بمظو هيئة } \\
\hline & & $r, \wedge T$ & $91, \varepsilon r$ & $0, v_{1}$ & $\cdots$ & $\cdot, \cdots$ & $\%$ & & \\
\hline & & . & $\cdot$ & 11 & $\cdot$ & $\cdot$ & ك & الرياضيات & \\
\hline & & $\cdot, \cdots$ & $\cdot, \cdots$ & $1 \cdots$ & $\cdot, \cdots$ & $\cdot, \cdots$ & $\%$ & & \\
\hline & & . & $\wedge$ & · & ro & . & ك5 & اللغة العربية & \\
\hline & & $\cdot, \cdots$ & $r \leq, r \leq$ & $\cdot, \cdots$ & $V_{0, V Y}$ & $\cdot, \cdots$ & $\%$ & & \\
\hline & & · & $\wedge$ & 1 & - & 1 & ك & اللغة الإنجليزية & \\
\hline & & $\cdot, \cdots$ & $\Lambda \cdot, \cdots$ & $1 \cdot, \cdots$ & $\cdots$ & $1 \cdot, \cdots$ & $\%$ & & \\
\hline & & 7 & $r \cdot$ & ir & 1 & $\cdot$ & ك5 & الإدارة والتخطيط & \\
\hline & & $10, \ldots$ & $0 ., \ldots$ & Mr,O. & r,o. & $\cdot, \cdots$ & $\%$ & & \\
\hline دالة عند مستوى & $1 \vee 9,9.1$ & 1 & r & r & $\cdot$ & $\cdot$ & ك5 & الكيمياء & يتعامل عضو هيئة \\
\hline$\cdot,+1$ & & $r, \wedge T$ & $91, \varepsilon r$ & $0, V_{1}$ & $\cdots$ & $\cdot, \cdots$ & $\%$ & & التدريس مع طلابه \\
\hline & & . & $\cdot$ & 11 & $\cdot$ & $\cdot$ & ك & الرياضيات & باحترام وتقدير · \\
\hline & & $\cdot, \cdots$ & $\cdot, \cdots$ & $1 \cdots$ & $\cdot, \cdots$ & $\cdot, \cdots$ & $\%$ & & \\
\hline & & $\cdot$ & $\wedge$ & $\cdot$ & ro & . & ك & اللغة العربية & \\
\hline & & $\cdot, \cdots$ & $r \leq, r \leq$ & $\cdot, \cdots$ & $\mathrm{V} 0, \mathrm{~V} T$ & $\cdot, \cdots$ & $\%$ & & \\
\hline & & . & $\wedge$ & 1 & $\cdot$ & 1 & ك5 & اللغة الإنجليزية & \\
\hline & & $\cdot, \cdots$ & $\Lambda \cdot, \cdots$ & $1 \cdot, \cdots$ & $\cdots$ & $1 \cdot, \cdots$ & $\%$ & & \\
\hline & & ir & 10 & ir & $\cdot$ & . & ك & الإدارة والتخطيط & \\
\hline & & $r \cdot, \cdot$ & $r v, o$. & rY,O. & $\cdot, \cdot$ & $\cdot, \cdots$ & $\%$ & & \\
\hline & & 1 & re & r & $\cdot$ & . & ك & 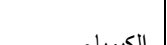 & \\
\hline & & 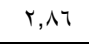 & $91, \varepsilon T$ & $0, V_{1}$ & $\cdots$ & $\cdot, \cdots$ & $\%$ & الحيةئ8 & \\
\hline & & . & $\cdot$ & 11 & . & . & ك5 & . 4 ill & \\
\hline & & $\cdot, \cdots$ & $\cdot, \cdots$ & $1 \ldots$ & $\cdot, \cdots$ & $\cdot, \cdots$ & $\%$ & الريلكئ & يعرض عضو هيئة \\
\hline دالة عند مستوى & $I V \varepsilon, Y, Y$ & · & $\wedge$ & $\cdot$ & ro & . & ك5 & اللغة العربية & التذريس \\
\hline$\cdot, \cdot 1$ & & $\cdot, \cdots$ & $r \varepsilon, Y \leqslant$ & $\cdot, \cdots$ & $V_{0, V T}$ & $\cdot, \cdots$ & $\%$ & | & الشخصية على الطلاب \\
\hline & & $\cdot$ & $\wedge$ & 1 & - & 1 & ك & اللغة الانحلنية & . \\
\hline & & $\cdot, \cdots$ & $\wedge \cdot, \cdots$ & $1 \cdot, \cdots$ & $\cdots$ & $1 \cdot, \cdots$ & $\%$ & 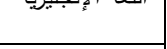 & \\
\hline & & 1. & 17 & $1 \leq$ & . & . & ك & | الإدارة & \\
\hline & & ro,, & $\varepsilon \cdot, \cdots$ & ro,... & $\cdot, \cdots$ & $\cdot, \cdots$ & $\%$ & والتخطيط & \\
\hline & & 1 & rt & r & · & . & 5 & 1 54 & \\
\hline & & 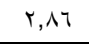 & $91, \varepsilon r$ & $0, V_{1}$ & $\cdots$ & $\cdot, \cdots$ & $\%$ & الحبمئع & \\
\hline & & $\cdot$ & $\cdot$ & 11 & . & . & ك & it il & \\
\hline & & $\cdot, \cdots$ & $\cdot, \cdots$ & $1 \ldots$ & $\cdot, \cdots$ & $\cdot, \cdots$ & $\%$ & -".r. & يبدي عضو هيئة \\
\hline دالة عند مستوى & $10 \Delta \Delta 71$ & . & $\wedge$ & $\cdot$ & ro & · & ك5 & |للاغة العبسة & التذريس قبوله اعتار \\
\hline$\cdot, \cdot 1$ & 年, & $\cdot, \cdots$ & $r \leq, r \leq$ & $\cdot, \cdots$ & $v_{0, V 7}$ & $\cdot, \cdots$ & $\%$ & | العقد السربية & طلابه عن التأخير \\
\hline & & . & $\wedge$ & 1 & . & 1 & ك5 & اللغة الانحليزية & و الغياب \\
\hline & & $\cdot, \cdots$ & $\wedge \cdot, \cdots$ & $1 \cdot, \cdots$ & $\cdots$ & $1 \cdot, \cdots$ & $\%$ & & \\
\hline & & 7 & 17 & 17 & 1 & 1 & 5 & | ل الإدارة & \\
\hline & & $10, \ldots$ & $\varepsilon \cdot, \cdots$ & $\varepsilon \cdot, \cdots$ & r,o. & r,o. & $\%$ & والتخطيط & \\
\hline
\end{tabular}


تقويم الأداء التدريسي لعضو هيئة التدريس بكلية التربية جامعة سرت في ليبيا من وجهة نظر طلبة الكلية كدخل لتحقيق جودة التعليم الجامعي.

\begin{tabular}{|c|c|c|c|c|c|c|c|c|c|}
\hline \multirow[t]{2}{*}{ الدلالة } & \multirow[t]{2}{*}{ قيمة كا } & \multicolumn{5}{|c|}{ نوع الاستجابة } & \multirow{2}{*}{ والتكرار } & \multirow{2}{*}{ الأقسام العلمية } & \multirow{2}{*}{ بنود المقياس } \\
\hline & & دائما & غالبا & احيانا & قليلا & نادرا & & & \\
\hline \multirow{10}{*}{ دالة عند مستوى } & \multirow{10}{*}{$17 ., 9 \leq 1$} & 1 & Tr & $r$ & . & . & ك & \multirow{2}{*}{ الكيمياء } & \multirow{10}{*}{ التقبل عضو هيئة } \\
\hline & & r,Aт & $91, \varepsilon r$ & $0, \times 1$ & $\cdots$ & $\cdot, \cdots$ & $\%$ & & \\
\hline & & . & . & 11 & . & . & ك5 & \multirow{2}{*}{ الرياضبات } & \\
\hline & & $\cdot, \cdots$ & $\cdot, \cdots$ & $1 \ldots$ & $\cdot, \ldots$ & $\cdot, \cdots$ & $\%$ & & \\
\hline & & . & $\wedge$ & . & ro & . & ك & \multirow{2}{*}{ اللغة العربية } & \\
\hline & & $\cdot, \ldots$ & $r \leq, r \leq$ & $\cdot, \cdots$ & $v 0, V_{T}$ & $\cdot, \cdots$ & $\%$ & & \\
\hline & & . & $\wedge$ & 1 & . & 1 & ك & \multirow{2}{*}{ اللغة الإنجليزية } & \\
\hline & & $\cdot, \cdots$ & $\wedge, \ldots$ & $1, \ldots$ & $\cdots$ & $1, \ldots$ & $\%$ & & \\
\hline & & v & iv & ir & 1 & r & ك5 & \multirow{2}{*}{ والتخطيط } & \\
\hline & & IV,O. & $\leqslant r, 0$. & Tr,O. & r,o. & $0, \ldots$ & $\%$ & & \\
\hline \multirow{10}{*}{ دالة عند مستوى } & \multirow{10}{*}{ 10N, TH } & 1 & r & 1 & 1 & . & ك5 & \multirow{2}{*}{ الكيمياء } & \multirow{10}{*}{ طبتجاوب عضو هيئة } \\
\hline & & r,AT & $91, \leqslant 5$ & Y,AT & $r, \wedge T$ & $\cdot, \cdots$ & $\%$ & & \\
\hline & & . & . & 11 & . & . & ك5 & \multirow{2}{*}{ الرياضيات } & \\
\hline & & $\cdot, \cdots$ & $\cdot, \cdots$ & $1 \ldots$ & $\cdot, \cdots$ & $\cdot, \cdots$ & $\%$ & & \\
\hline & & · & $\wedge$ & · & ro & · & ك & $\because \|$ & \\
\hline & & $\cdot, \cdots$ & $r \leq, Y \leqslant$ & $\cdot, \cdots$ & Vo,v & $\cdot, \cdots$ & $\%$ & السعة الهربية & \\
\hline & & . & 9 & . & 1 & . & ك5 & & \\
\hline & & $\cdot, \cdots$ & $q,, \ldots$ & $\cdot, \cdots$ & $1 \cdot, \ldots$ & $\cdot, \cdots$ & $\%$ & السعه الإحجليريكة & \\
\hline & & o & 11 & ir & $\varepsilon$ & $v$ & ك & الإدارة & \\
\hline & & Ir,o. & rV,O. & Tr,O. & $1 \cdot, \ldots$ & IV,O. & $\%$ & والتخطيط & \\
\hline \multirow{10}{*}{ دالة عند مستوى } & \multirow{10}{*}{$1 \leq 7, \cdots \wedge$} & 1 & Tr & 1 & 1 & . & ك5 & \multirow{2}{*}{ الكيمياء } & \multirow{10}{*}{ 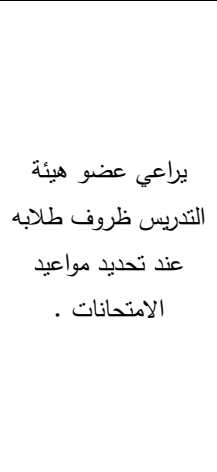 } \\
\hline & & Y,Aт & $91, \leqslant \pi$ & Y,Aт & r,Aт & $\cdot, \cdots$ & $\%$ & & \\
\hline & & . & . & 11 & . & . & ك & \multirow{2}{*}{ الرياضيات } & \\
\hline & & $\cdot, \cdots$ & $\cdot, \cdots$ & $1 \ldots$ & $\cdot, \cdots$ & $\cdot, \cdots$ & $\%$ & & \\
\hline & & . & $\Lambda$ & . & ro & . & 5 & \multirow{2}{*}{ اللغة العربية } & \\
\hline & & $\cdot, \cdots$ & $r \leqslant, Y \leqslant$ & $\cdot, \cdots$ & $\mathrm{V} 0, V_{T}$ & $\cdot, \cdots$ & $\%$ & & \\
\hline & & · & 9 & · & 1 & . & ك & \multirow{2}{*}{ اللغة الإنجليزية } & \\
\hline & & $\cdot, \cdots$ & $9 \cdot, \cdots$ & $\cdot, \cdots$ & $1 \cdot, \cdots$ & $\cdot, \cdots$ & $\%$ & & \\
\hline & & $r$ & ir & ir & 7 & 7 & ك5 & \multirow{2}{*}{ الإدارة والتخطيط } & \\
\hline & & $v, 0$. & $\Gamma \cdot, \ldots$ & r.,O. & $10, \ldots$ & $10, \ldots$ & $\%$ & & \\
\hline
\end{tabular}

بتحليل بيانات بطاقة تقويم الأداء التنريسي في بُعدها المتعلق

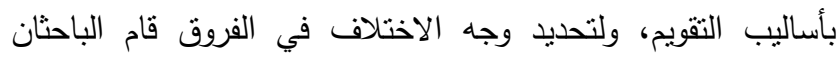

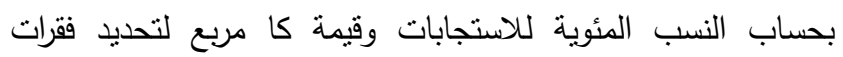

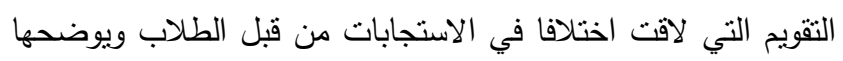

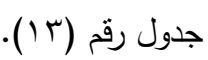
نستتنج من بيانات الجدول (r ا ( ) والمتعلق بالنتائج الاحصائية

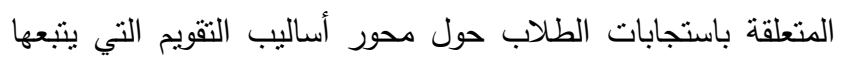
عضو هيئة التدريس، فقد نبين من استجابات الطلاب أنّ عضو هيئة النّات

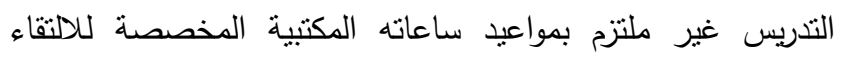

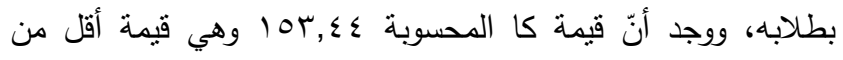
القيمة الجدولية، وبذللك نلاحظ عدم وجود فروق ذات دلالة إحصائية، كذللك عبارة حرص عضو هيئة التدريس على الحياد في تقدير درجات

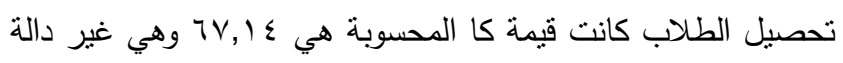

تشير بيانات الجدول (r I) والمتعلق باستجابات الطلاب حول تقويم الأداء التدريسي لعضو هيئة التدريس في بُعدها المتعلق بالسمات

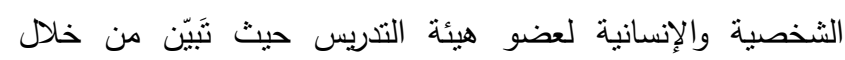

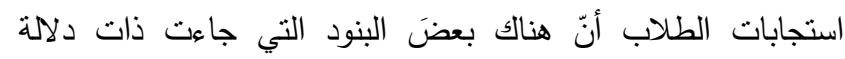

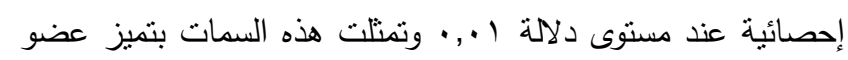

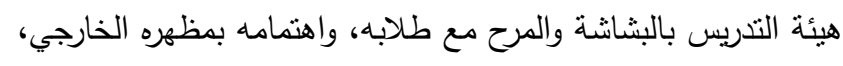
وتعامل عضو هيئة التدريس باحترام مع طلابه، حيث كانت قيمة كابنه المحسوبة أكبر من قيمة كا الجدولية.

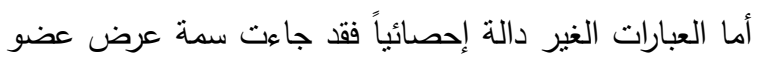

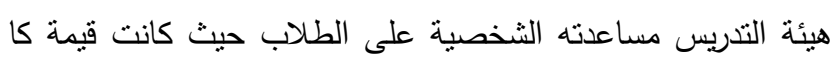
المسوبة أقل من القيمة الجدولية. ثالثاً: تقويم الأداء التدريسي لعضو هيئة التئة التدريس من جانب

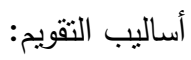


أما بالنسبة إلى مدى تتويع عضو هيئة التدريس في أساليب على أن يتضمن الامتحان على موضوعات ثم شرحها خلا المحاضرات، وتميز أسئلة الامتحان بالوضوح، وحرص عضو هيئة التانة

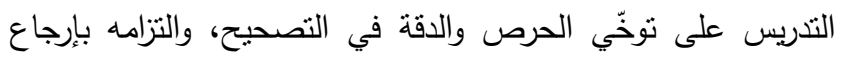
تقويم أداء الطلاب، وحرص عضو هيئة التدريس في استلام أنشطة أوراق الامتحانات إلى الطلاب، حيث وجدت قيمة كا المحسوبة أعلى

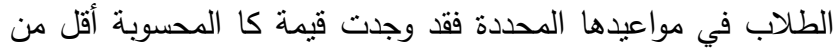
من قيمتها الجدولية مما يؤكد وجود فروق ذات دلالة إحصائية في قيمتها الجدولية، وهذا يؤكد عدم وجود فروق ذات دلالة إحصائية في استجابات الطلاب حول هذه السمات والتزام عضو هيئة التدريس بها. استجابات الطلاب حول هذه السمات وعدم التزام عضو هيئة التدريس بها. أما بالنسبة للصفات الأخرى مثل حرص عضو هيئة التدريس هابس

جدول (ب ا ) يوضح استجابات تقويم الأداء التدريسي لعضو هيئة التدريس في بعد أساليب التقويم كأحد جوانب التقويم والفروق في الاستجابات حسب الأقسام العلمية.

\begin{tabular}{|c|c|c|c|c|c|c|c|c|c|}
\hline \multirow[t]{2}{*}{ الدلالة } & \multirow[t]{2}{*}{ قيمة كا } & \multicolumn{5}{|c|}{ نوع الاستجابة } & \multirow{2}{*}{ والنسبة } & \multirow{2}{*}{ الاقسام } & \multirow{2}{*}{ بنود المقياس } \\
\hline & & دائما & غالبا & احيانا & قليلا & نادرا & & & \\
\hline \multirow{10}{*}{ غير دالة عند مستوى } & \multirow{10}{*}{$\wedge \varepsilon, 1 Y \varepsilon$} & . & tr & 1 & v & . & ك5 & \multirow{2}{*}{ الكيمباء } & \multirow{10}{*}{ 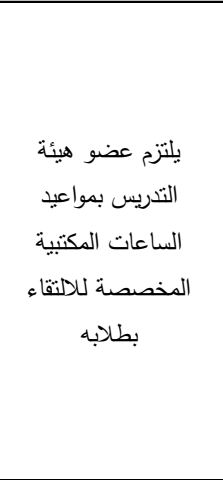 } \\
\hline & & $\cdot, \cdots$ & $V V, 1 \leq$ & $r, \wedge T$ & $r \cdot, \ldots$ & $\cdot, \cdots$ & $\%$ & & \\
\hline & & . & . & . & $\wedge$ & $r$ & ك5 & \multirow{2}{*}{ الرياضيات } & \\
\hline & & $\cdot, \cdots$ & $\cdot, \cdot$ & $\cdot, \cdots$ & VY,VY & TV,YA & $\%$ & & \\
\hline & & . & . & . & ro & $\wedge$ & ك5 & \multirow{2}{*}{ اللغة العربية } & \\
\hline & & $\cdot, \cdots$ & $\cdot, \cdot$, & $\cdot, \cdots$ & $v_{0}, V_{7}$ & $r \leqslant, Y \varepsilon$ & $\%$ & & \\
\hline & & . & 1 & . & $\varepsilon$ & . & ك5 & \multirow{4}{*}{ الإلنجليزية } & \\
\hline & & $\cdot, \cdots$ & $7 \cdot, \ldots$ & $\cdot, \cdots$ & $\varepsilon \cdot, \cdot$, & $\cdot, \cdot$ & $\%$ & & \\
\hline & & . & . & 17 & 17 & $\wedge$ & ك5 & & \\
\hline & & $\cdot, \cdot$, & $\cdot, \cdots$ & $\varepsilon \cdot, \cdot$. & $\varepsilon \cdot, \cdot \cdot$ & r.o. & $\%$ & & \\
\hline \multirow{10}{*}{ دالة عند مستوى } & \multirow{10}{*}{ 101,Aro } & 1 & r & 1 & 1 & . & ك5 & \multirow{2}{*}{ الكيمياء } & \multirow{10}{*}{ خلال مضوعات نم شرحها الامتحان } \\
\hline & & $r, \wedge T$ & $91, \leqslant r$ & $r, \wedge T$ & $r, \wedge r$ & $\cdot, \cdots$ & $\%$ & & \\
\hline & & . & . & 11 & . & . & ك5 & \multirow{2}{*}{ الرياضيات } & \\
\hline & & $\cdot, \cdots$ & $\cdot, \cdot$ & $1 \ldots$ & $\cdot, \cdots$ & $\cdot, \ldots$ & $\%$ & & \\
\hline & & . & $\wedge$ & . & ro & . & ك5 & الآة & \\
\hline & & $\cdot, \cdots$ & $r \leq, Y \leqslant$ & $\cdot, \cdots$ & $v_{0, v 4}$ & $\cdot, \cdots$ & $\%$ & اللعه العربيه & \\
\hline & & . & 9 & . & 1 & . & ك5 & اللغة & \\
\hline & & $\cdot, \cdots$ & $q \cdot, \ldots$ & $\cdot, \cdots$ & $1 \cdot, \ldots$ & $\cdot, \ldots$ & $\%$ & الإنجليزية & \\
\hline & & $\wedge$ & 11 & 11 & 1 & $r$ & ك5 & الإدارة & \\
\hline & & $r_{\cdot}, \ldots$ & $\leq 0, \ldots$ & $r V, O$. & r.o. & $0, \cdots$ & $\%$ & والتخطيط & \\
\hline \multirow{10}{*}{ دالة عند مستوى } & \multirow{10}{*}{$17 V, 1 \leqslant r$} & 1 & זr & 1 & . & . & ك5 & \multirow{2}{*}{ الكيمياء } & \multirow{10}{*}{ التمبز أسئلة امتحانات. } \\
\hline & & $r, \Lambda T$ & $q \varepsilon, q_{q}$ & $r, \lambda T$ & $\cdot, \cdots$ & $\cdot, \cdots$ & $\%$ & & \\
\hline & & . & . & 11 & . & . & ك5 & \multirow{2}{*}{ الرياضيات } & \\
\hline & & $\cdot, \cdots$ & $\cdot, \cdot$, & $1 \ldots$ & $\cdot, \cdot$ & $\cdot, \cdots$ & $\%$ & & \\
\hline & & . & $\wedge$ & . & ro & · & ك & اللغة العبشة & \\
\hline & & $\cdot, \cdots$ & $r \varepsilon, Y \leqslant$ & $\cdot, \cdot$, & $V_{0, V 7}$ & $\cdot, \cdot$ & $\%$ & . & \\
\hline & & . & 9 & . & 1 & . & ك5 & اللغة & \\
\hline & & $\cdot, \cdots$ & $q_{\cdot, \ldots}$ & $\cdot, \cdots$ & $1 \cdot, \ldots$ & $\cdot, \cdot$ & $\%$ & الإنجليزية & \\
\hline & & $v$ & ir & ir & r & 0 & ك5 & الإدارة & \\
\hline & & iv,o. & rY,O. & rr,O. & $0, \cdot \cdot$ & Ir,O. & $\%$ & والتخطيط & \\
\hline & & . & rr & $r$ & . & . & ك5 & SIIt & \\
\hline & & $\cdot, \cdot$, & $91, \varepsilon \pi$ & $\Lambda, 0 \mathrm{~V}$ & $\cdot, \cdots$ & $\cdot, \cdots$ & $\%$ & الخيمياء & \\
\hline & & . & . & 11 & . & . & s & -1.14 & \\
\hline & & $\cdot, \cdot$ & $\cdot, \cdots$ & $1 \ldots$ & $\cdot, \cdot$ & $\cdot, \cdots$ & $\%$ & الريطيات & يحرص عضو هيئة \\
\hline دالة عند مسنوى & IVY, VV & . & . & 1 & rt & . & ك5 & ة & الندريس على توخي \\
\hline$\cdot, \cdot 1$ & & $\cdot, \cdot$ & $\cdot, \cdot$ & $r, \cdot r$ & $97,9 \vee$ & $\cdot, \cdots$ & $\%$ & اللعه العربية & الدقة في تصحيح أوراق \\
\hline & & . & $r$ & . & $\wedge$ & . & ك5 & اللغة & الامتحانات . \\
\hline & & $\cdot, \cdot$, & $r \cdot, .$. & $\cdot, \cdot$, & $\Lambda_{\cdot}, \ldots$ & $\cdot, \cdots$ & $\%$ & الإنجليزية & \\
\hline & & $\wedge$ & 10 & 0 & 11 & 1 & ك5 & الإدارة & \\
\hline & & $r \cdot, \ldots$ & $r v, 0$. & $1 r, 0$. & $T V, O$. & r,o. & $\%$ & والتخطيط & \\
\hline
\end{tabular}


تقويم الأداء التدريسي لعضو هيئة التدريس بكلية التربية جامعة سرت في ليبيا من وجهة نظر طلبة الكلية كمخل لتحقيق جودة التعليم الجامعي.

\begin{tabular}{|c|c|c|c|c|c|c|c|c|c|}
\hline الدلالة & قيمة كا & & & ع الاستج & & & التكرار & الاقسام & \\
\hline & & دائما & غالبا & احيانا & قليلا & نادرا & والنسبة & العلمية & بوله المعيساس \\
\hline \multirow{10}{*}{ غير دالة عند مستوى } & \multirow{10}{*}{$T V, 1 \leq$} & . & . & . & rr & r & ك5 & \multirow{2}{*}{ الكيمياء } & \multirow{10}{*}{ 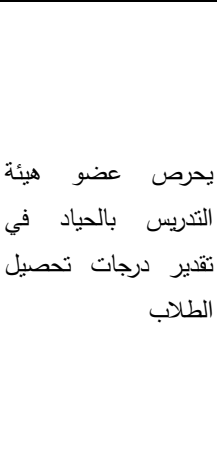 } \\
\hline & & $\cdot, \cdots$ & $\cdot, \cdots$ & $\cdot, \cdots$ & $\wedge \varepsilon, 0$ & 10,0 & $\%$ & & \\
\hline & & . & . & 11 & . & . & ك5 & \multirow{2}{*}{ الرياضيات } & \\
\hline & & $\cdot, \cdots$ & $\cdot, \cdots$ & $1 \ldots$ & $\cdot, \cdots$ & $\cdot, \cdots$ & $\%$ & & \\
\hline & & . & . & 1 & rr & . & ك5 & للافة العصبة & \\
\hline & & $\cdot, \cdots$ & $\cdot, \cdots$ & $r, \cdot r$ & $97,9 \vee$ & $\cdot, \cdots$ & $\%$ & اللعه العربية & \\
\hline & & . & . & $r$ & v & . & 5 & اللغة & \\
\hline & & $\cdots j$ & $\cdot, \cdots$ & $r \cdot, \ldots$ & $v \cdot, \ldots$ & $\cdot, \cdots$ & $\%$ & الإنجليزية & \\
\hline & & 9 & 10 & r & ir & 1 & ك5 & الإدارة & \\
\hline & & Yr,O. & $r v, 0$. & $\mathrm{v}, \mathrm{O}$. & $r \cdot, \ldots$ & r,o. & $\%$ & والتخطيط & \\
\hline \multirow{10}{*}{ دالة عند مستوى } & \multirow{10}{*}{$1 \wedge 0, r \ldots$} & . & r & $r$ & . & . & 5 & \multirow{2}{*}{ الكيمياء } & \multirow{10}{*}{ 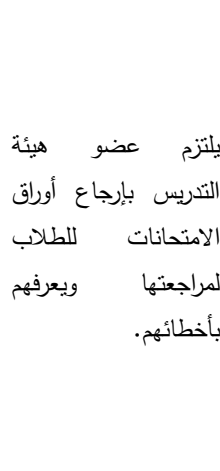 } \\
\hline & & $\cdot, \cdots$ & $q \leq, Y q$ & $0, \times 1$ & $\cdot, \cdots$ & $\cdot, \cdots$ & $\%$ & & \\
\hline & & . & . & 11 & . & . & ك5 & \multirow{2}{*}{ الرياضيات } & \\
\hline & & $\cdot, \cdots$ & $\cdot, \cdots$ & $1 \ldots$ & $\cdot, \cdots$ & $\cdot, \cdots$ & $\%$ & & \\
\hline & & . & . & 1 & r & . & ك & لإنة لالمبا & \\
\hline & & $\cdot, \cdots$ & $\cdot, \cdots$ & $r, \cdot r$ & $97,9 \vee$ & $\cdot, \cdots$ & $\%$ & 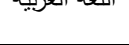 & \\
\hline & & . & . & r & $\wedge$ & . & ك & اللغة & \\
\hline & & $\cdots j$ & $\cdot, \cdots$ & $r \cdot, \cdots$ & $\wedge \cdot, \cdots$ & $\cdot, \cdots$ & $\%$ & الإنجليزية & \\
\hline & & IT & 1. & 1 & ir & . & ك5 & الإدارة & \\
\hline & & $r \cdot, .$. & ro,... & $10, \ldots$ & $r \cdot, \ldots$ & $\cdot, \cdots$ & $\%$ & والتخطيط & \\
\hline \multirow{10}{*}{ غير دالة عند مستوى } & \multirow{10}{*}{ Ar,Ir } & . & . & . & r & rr & ك & \multirow{2}{*}{ الكيمباء } & \multirow{10}{*}{ 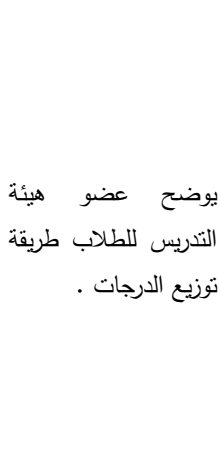 } \\
\hline & & $\cdot, \cdots$ & $\cdot, \cdots$ & $\cdot, \cdots$ & $0, V_{1}$ & $q \varepsilon, Y q$ & $\%$ & & \\
\hline & & . & . & 11 & . & . & ك & \multirow{2}{*}{ الرياضيات } & \\
\hline & & $\cdot, \cdots$ & $\cdot, \cdots$ & $1 \ldots$ & $\cdot, \cdots$ & $\cdot, \cdots$ & $\%$ & & \\
\hline & & . & . & 1 & r & . & ك & ة & \\
\hline & & $\cdot, \cdots$ & $\cdot, \cdots$ & $r, \cdot r$ & $97,9 \vee$ & $\cdot, \cdots$ & $\%$ & التعش المعربية & \\
\hline & & . & - & $r$ & $\wedge$ & . & ك5 & اللغة & \\
\hline & & $\cdots j$ & $\cdot, \cdots$ & $r \cdot, \cdots$ & $\wedge \cdot, \cdots$ & $\cdot, \cdots$ & $\%$ & الإنجليزية & \\
\hline & & v & 17 & $r$ & ir & 1 & ك5 & الإدارة & \\
\hline & & IV,o. & $\varepsilon \cdot, \cdots$ & $\mathrm{v}, \mathrm{O}$. & rr,o. & $r, 0$. & $\%$ & والتخطيط & \\
\hline \multirow{10}{*}{ غير دالة عند مسنوى } & \multirow{10}{*}{17,11} & . & . & . & r & rr & ك & 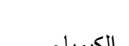 & \multirow{10}{*}{ 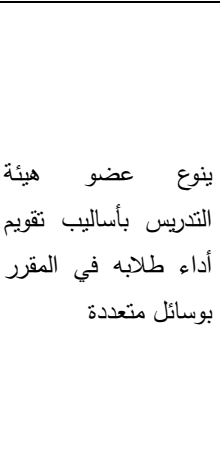 } \\
\hline & & $\cdot, \cdots$ & $\cdot, \cdots$ & $\cdot, \cdots$ & $0, \times 1$ & $q \leq, r q$ & $\%$ & & \\
\hline & & . & . & . & . & 11 & ك5 & & \\
\hline & & $\cdot, \cdots$ & $\cdot, \cdots$ & $\cdot, \cdots$ & $\cdot, \cdots$ & $1 \cdots, \cdots$ & $\%$ & الريك" & \\
\hline & & . & . & . & 1 & rr & ك5 & & \\
\hline & & $\cdot, \cdots$ & $\cdot, \cdots$ & $\cdot, \cdots$ & $r, r$ & $97, V$ & $\%$ & عربيه & \\
\hline & & - & . & . & r & $\wedge$ & 5 & اللغة & \\
\hline & & $\cdots j$ & $\cdots j$ & $\cdot, \cdots$ & $r_{\cdot}, \cdots$ & $\wedge \cdot, \cdots$ & $\%$ & الإنجليزية & \\
\hline & & . & . & - & r & rᄉ & ك5 & الإدارة & \\
\hline & & $\cdots j$ & $\cdots j$ & $\cdot, \cdots$ & $0, \ldots$ & $90, \ldots$ & $\%$ & والتخطيط & \\
\hline & & r & $r$ & $r$. & . & . & ك5 & & \\
\hline & & $0, V$ & $\wedge, 0$ & $\wedge 0, \mathrm{~V}$ & $\cdots j \cdot$ & $\cdot, \cdots$ & $\%$ & برياء & \\
\hline & & 1 & r & $\wedge$ & $\cdot$ & . & ك & & \\
\hline & & $9, \cdots$ & $19, \cdots$ & $V_{r}, \cdots$ & $\cdots j$ & $\cdot, \cdots$ & $\%$ & الريطبات & بكلف عضو هيئة \\
\hline دالة عند مستوى & r & 0 & 0 & $r$. & $r$ & . & ك & iI & التدريس الطلاب بأوراق \\
\hline$\cdot,+1$ & 1,16 & $1 \leq, r$ & $1 \leqslant, r$ & ov, 1 & $\wedge, 0$ & $\cdot, \cdots$ & $\%$ & معه السعبيد & عملوبحوث تتعلق \\
\hline & & r & r & 0 & . & . & ك & 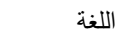 & بالمقرر الدراسي \\
\hline & & $r \cdot, \cdots$ & $r \cdot, \cdots$ & $0 ., \cdots$ & $\cdot, \cdots$ & $\cdot, \cdots$ & $\%$ & الإنجليزية & \\
\hline & & $\varepsilon$ & $r$. & 0 & 1 & . & ك5 & الإدارة & \\
\hline & & $1 \cdot, \cdots$ & $v_{0}, \ldots$ & $M, 0$ & $r, 0$ & $\cdot, \cdots$ & $\%$ & والتخطيط & \\
\hline
\end{tabular}


المجلة الدولية لضمان الجودة - المجلد الثاني - العدد الثاني، 19 ــr.

\begin{tabular}{|c|c|c|c|c|c|c|c|c|c|}
\hline \multirow[t]{2}{*}{ الدلالة } & \multirow[t]{2}{*}{ قيمة كا } & \multicolumn{5}{|c|}{ نوع الاستجابة } & \multirow{2}{*}{ والنكبة } & \multirow{2}{*}{ الاقسام } & \multirow{2}{*}{ بنود المقياس } \\
\hline & & دائما & غالبا & احيانا & قليلا & نادرا & & & \\
\hline \multirow{10}{*}{ غير دالة عند مستوى } & \multirow{10}{*}{ vo, 11} & . & . & 1 & $r$ & $r$. & ك5 & \multirow{2}{*}{ الكيمياء } & \multirow{10}{*}{ 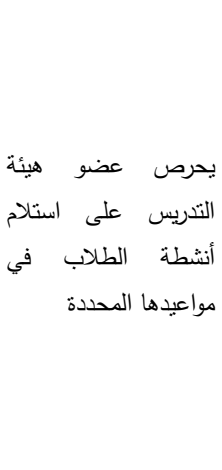 } \\
\hline & & $\cdot, \cdots$ & $\cdot, \cdots$ & $r, r$ & $7, \mathrm{~V}$ & $9 \cdot, 9$ & $\%$ & & \\
\hline & & · & . & 1 & r & $\wedge$ & ك5 & \multirow{2}{*}{ الرياضيات } & \\
\hline & & $\cdot, \cdots$ & $\cdot, \cdots$ & 9,9 & 11,11 & $V Y, V$ & $\%$ & & \\
\hline & & . & . & 1 & $\varepsilon$ & $r y$ & ك5 & \multirow{2}{*}{ اللغة العربية } & \\
\hline & & $\cdot, \cdots$ & $\cdot, \cdots$ & $r, r$ & $1 r, 9$ & גז, & $\%$ & & \\
\hline & & . & . & r & r & 7 & ك5 & \multirow{2}{*}{ اللإنجليزية } & \\
\hline & & $\cdot, \cdots$ & $\cdot, \cdots$ & $r \cdot, \cdots$ & $r_{\cdot,}, \cdots$ & ฯ., . & $\%$ & & \\
\hline & & . & . & . & 1. & $r$. & ك5 & \multirow{2}{*}{ والإدارة } & \\
\hline & & $\cdot, \cdots$ & $\cdot, \cdots$ & $\cdot, \cdots$ & $r_{0}, \ldots$ & $v_{0}, \ldots$ & $\%$ & & \\
\hline
\end{tabular}

عضو هيئة التدريس بين ما يقوم بتدريسه وبين ما يطبق

$$
\text { في الحياة. }
$$

نتائج الاراسة ومقترحاتها:

نتائج الاراسة:

أفادت الدراسة أيضاً بعدم التزام عضو هيئة التدريس بالساعات المكتية للالنقاء بطلابه، وعدم التتوع في أساليب

$$
\text { الثقويم واقتصارها على الامتحانات. }
$$

وفي ضوء ما توصلت إليه الاراسة من نتائج يقام الباحثان

المقترحات الآتية:

نتيجة لما بحققه نظام تقويم الأداء لأعضاء هيئة التدريس الأه من الوقوف على أوجه القصور في الأداء ومحاولة الاستفادة منها بما يقدمه من تغذية راجعة لهم وتحفيزهم الهاه

$$
\text { على نطوير ذاتهم بشكل مستمر . }
$$

أن تعمل الأقسام العلمية بالكليات على ضدرئل فرورة أن ينقبل

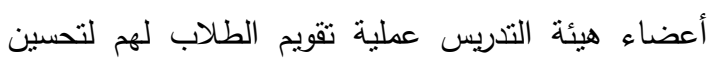

$$
\text { مستوى الأداء. - معناء }
$$

توعية الطلاب بأهمية أخذ آرائهم في تقويم أعضاء هيئة

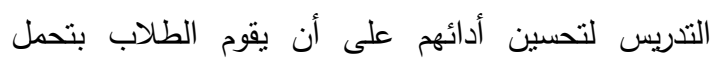
مسؤولياتهم في عملية التقويم وذلك بأن يكونوا موضوعيين في مختلف جوانب الثقويم. إعداد برامج تدرييية لأعضاء هيئة التدريس في مهارات التدريس والتعامل مع الطلاب واستخدام التقنيات التربوية وتتجيع برامج التتمية المهنية لهم بشكل مستمر .

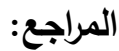

1. الجراح، عبد الناصردياب، الثريفين، نضال كمال،

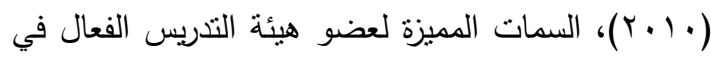

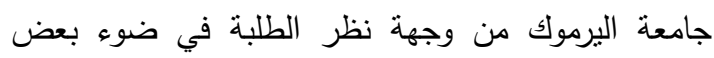

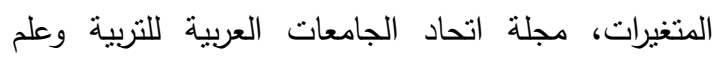
النفس، الجمعية العلمية لكليات التربية في الجامعات العربية، كلية التربية، جامعة دمثق، المجلد الثامن، العدد

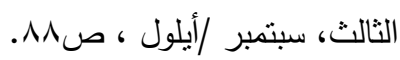

في ضوء الإطار النظري للاراسة وما نوصلت إليه في جانبه الميداني يمكن أن نستخلص النتائج التالية:

عدم وجود فروق ذات دلالة إحصائية عند مستوى دلالة ا.,. • تُعزى لمتغير جنس الطلاب أي بين الذكور و الإناث في استجاباتهم حول تقويم أداء عضو هيئة التدريس. عدم وجود فروق ذات دلالة إحصائية عند مستوى دلالة

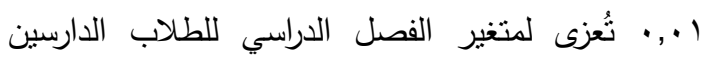
بفصل الخريف والدارسين بفصل الربيع في استجاباتهم حول تقويم أداء عضو هيئة التدريس. عدم وجود فروق ذات دلالة إحصائية عند مستوى دلالة

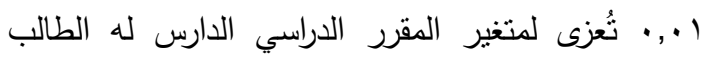

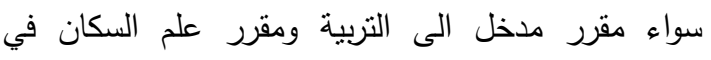
استجاباتهم حول تقويم أداء عضو هيئة النتريس.

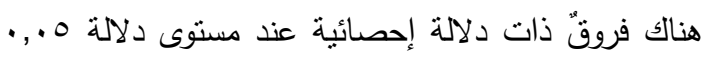

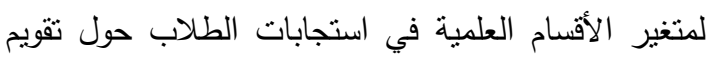

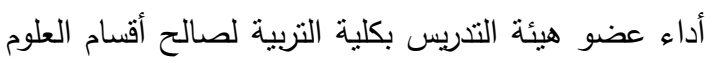

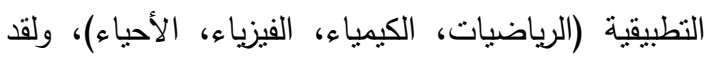
تبين من الدراسة الميدانية أيضا أن نقويم أداء عضو هيئة

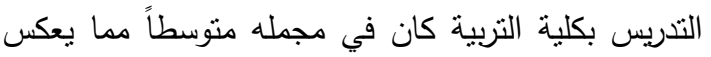
عدم رضا الطلاب عن هذا الأداء. أما عن مدى التزام عضو هيئة التدريس بخطة المقرر

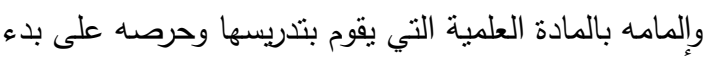
المحاضرة في موعدها، فقد تذبذبت آراء الطلاب في إعطاء وصف واقعي لعضو هيئة التدريس من حيث امتلاكه لهذه

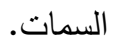
كان من نتائج الدراسة الميدانية عدم استخدام عضو هيئة

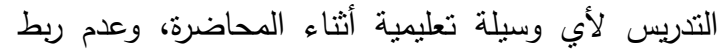




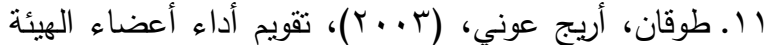

التدريسية من قبل الطلبة وبيان مدى تأثير المتغيرات

الديموغرافية فيها بجامعة النجاح الوطنية بنابلس، رسالة

ماجسنير، غير منشورة، كلية الدراسات العلبا، جامعة

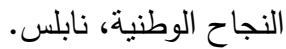

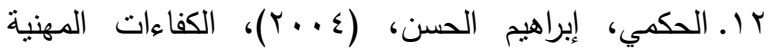

المنطلبة للأستاذ الجامعي من وجهة نظر طلابه وعلاقتها

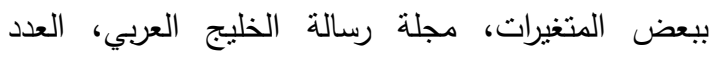

التسعون، السنة الرابعة والعشرون، الرياض.

rا. القرني، على بن سعد، وآخرون، (0. . ب)، تقويم أداء

عضو هيئة التدريس بجامعة الملك سعود، نظوير أداء

الجامعات العربية في ضوء معايير الجودة الثشاملة ونظم

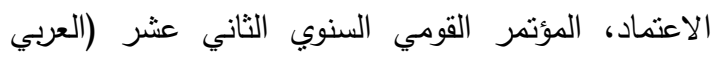

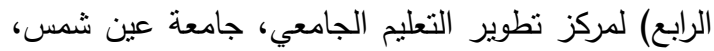

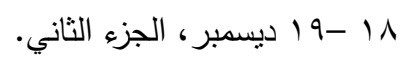

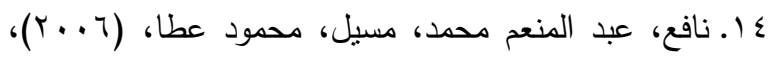

نظام تقويم أداء عضو هيئة التدريس بالجامعات المصرية

في ضوء خبرة بعض الجامعات الأخرى، مرجع سبق ذكره.

\section{Translated References:}

1. Al-Jarrah, Abdul Nasser Deyab, AlSharifeen \&Nidal Kamal (2010), Distinctive Features of an Effective Faculty Lectures at Yarmouk University from Students' Viewpoint Depend on Some Variables. Journal of the Federation of Arab Universities for Education and Psychology, Scientific Association of Colleges of Education in Arab Universities Faculty of Education, Damascus University, Volume VIII, Number 3, September, p. 88.

2. Al-Shami, Ibrahim Abdullah, (1994), Some of the Tasks of Faculty Lectures \& the Reality of their Performance as Perceived by Students and Lectures of King Faisal University in Al-Ahsa, Journal of the Center for Educational Research, the sixth issue, third year, $\mathrm{p} 103$.

3. Bukhari, Sultan, (2006), Evaluation of the Performance of Faculty Lectures at the University of Umm Al-Qura, Journal of the World of Education, the Association of Modern Education, Journal of the World of Education, Association of Modern Education, the number of twenty, seventh year, October 2006, Cairo, p 67.

4. Nafea, Abdel Moneim Mohamed, Maseel, Mahmoud Atta, (2006), The System of Evaluation of the Performance of the r. الثامي، إبراهيم عبد الله، (؟991)، بعض مهام أعضاء هيئة التدريس و واقع أدائها كما يدركه الطلاب والأعضاء بجامعة الملك فيصل بالإحساء، مجلة مركز البحوث

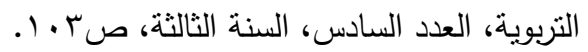

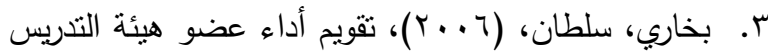
بجامعة أم القرى، مجلة عالم التربية، رابطة التربية الحديثة، مجلة عالم التربية، رابطة التربية الحديثة، العدد العشرون،

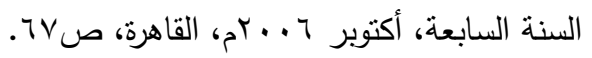

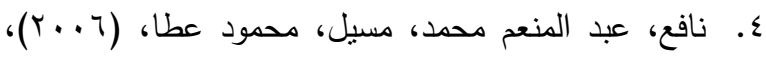
نظام تقويم أداء عضو هيئة التنريس بالجامعات المصرية في ضوء خبرة بعض الجامعات الأخرى، مجلة التربية،

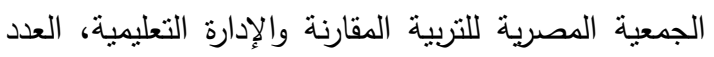

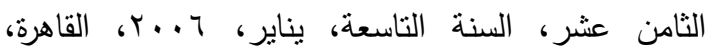
ص ص

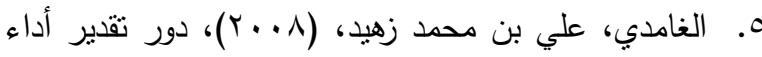
عضو هيئة التدريس الجامعي لمهامه التعليمية، جودة الأداء

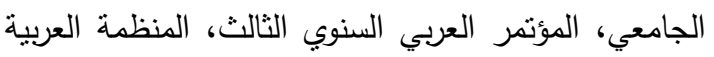
للتتمية الإدارية، الثشارقة، دولة الإمارات العربية المتحدة، 1

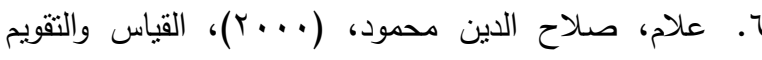

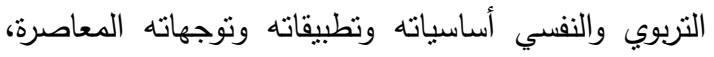

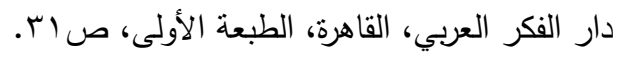

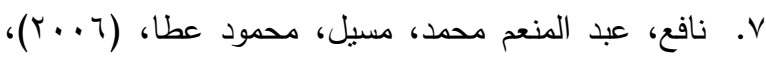

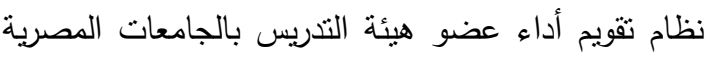
في ضوء خبرة بعض الجامعات الأخرى، مرجع سبق ذكره، لهاء

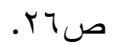

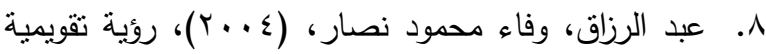
جديدة لأداء عضو هيئة التدريس الجامعي في ضوء كل من أهداف مؤسسات التعليم الجامعي والتحديات، ورقة عمل التهاء

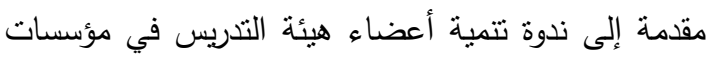
التعليم العالي التحديات والتطوير، كلية التنربية، جامعة

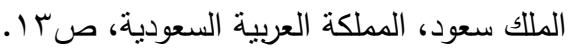

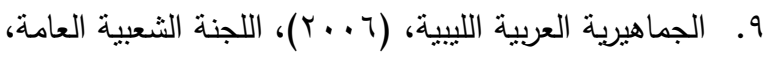

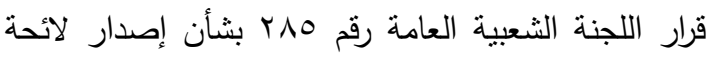
أعضاء هيئة التنريس الوطنيين بمؤسسات التعليم العالي،

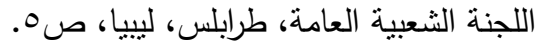

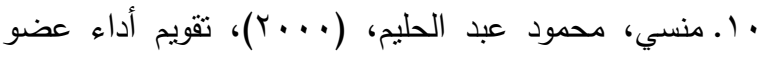
هيئة التنريس من وجهة نظر طلابه كمدخل لتحقيق جودة

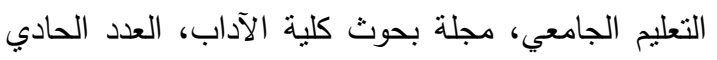
والأربعون، ابريل . . . ؟، كلية الآداب، جامعة المنوفية. 
issuance of the list of national teaching staff in higher education institutions, General People's Committee, Tripoli, Libya, p. 5.

10. Mansy, Mahmoud Abdel Halim, (2000), Evaluation of the Performance of the Faculty Lectures from the Perspective of his Students as an Entrance to Achieve the Quality of University Education, Journal of the Faculty of Arts Research, No. 41, April 2000, Faculty of Arts, University of Menoufia.

11. Toukan, Areej Awni, (2003), Evaluation of the Performance of Faculty Members by Students and the Extent of Impact of Demographic Variables in An-Najah National University, Nablus, Master Thesis, unpublished, Faculty of Graduate Studies, An-Najah National University, Nablus.

12. Al-Hakami, Ibrahim Al-Hassan, (2004), The Professional Competencies Required for the University Professor from the Perspective of his Students and their Relationship to Some Variables, Journal of the Arab Gulf message, No. ninety, twentyfourth year, Riyadh.

13. Al-Qarni, Ali Bin Saad, et al, (2005), Evaluation of the Performance of the Faculty Lectures at King Saud University, the Development of the Performance of Arab Universities in the Light of Comprehensive Quality Standards and Accreditation Systems, December 18-19, second part.

14. Nafea, Abdel Moneim Mohamed, Maseel, Mahmoud Atta, (2006b), The System of Evaluating the Performance of Faculty Lectures in Egyptian Universities in the Light of the Experience of Some Other Universities,
Faculty Lectures in Egyptian Universities in the Light of the Experience of Some Other Universities, Journal of Education, Egyptian Society for Comparative Education and Educational Administration, No. 18, ninth year, January , 2006, Cairo, p. 47.

5. Al-Ghamdi, Ali bin Mohammed Zuhaid, (2008), The Role of Appreciating the Performance of Academic Staff for his Educational Tasks, Quality of University Performance, Third Annual Arab Conference, Arab Organization for Administrative Development, Sharjah, United Arab Emirates, 13-17 /4/ 2008, p. 65.

6. Allam, Salah al-Din Mahmoud, (2000), The Measurement and Evaluation of Educational and Psychological Fundamentals, Applications and Contemporary Trends, Dar al-Fikr alArabi, Cairo, first edition, p. 31.

7. Nafie, Abdel Moneim Mohammed, Messil, Mahmoud Atta, (2006a), The System of Evaluation of the Performance of the Faculty Lectures in Egyptian Universities in the Light of the Experience of Some Other Universities, P. 26.

8. Abdul Razzaq, Wafa Mahmoud Nassar, (2004), A New Evaluation Vision of the Performance of the Faculty Member in the Light of Both the Objectives of University Education Institutions and Challenges, a paper presented to the symposium on the development of faculty members in higher education institutions Challenges and development, Faculty of Education, King University Saud, Saudi Arabia, p. 13.

9. Libyan Arab Jamahiriya, (2006), General People's Committee, Decision of the General People's Committee No. 285 on the 